\title{
Efeito do ensino de golpes e sequências de golpes de Taekwondo sobre luta simulada
}

\author{
Renata Penna Borges Nunes Cambraia
}

Orientador: Profa. Dra. Elenice S. Hanna

Dissertação apresentada ao
Programa de Pós-Graduação em
Ciências do Comportamento, do
Departamento de Processos
Psicológicos Básicos, Instituto de
Psicologia, Universidade de
Brasília, como parte dos requisitos
para obtenção do grau de Mestre em
Ciências do Comportamento (Área
de Concentração: Análise do
Comportamento).

Brasília, janeiro de 2015 


\section{Índice}

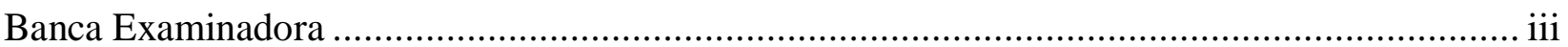

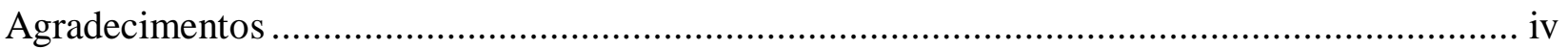

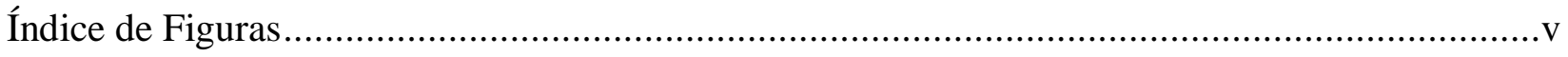

Índice de Tabelas .................................................................................................. vi

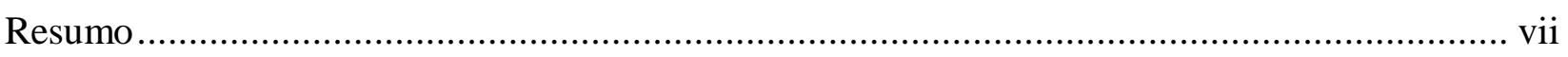

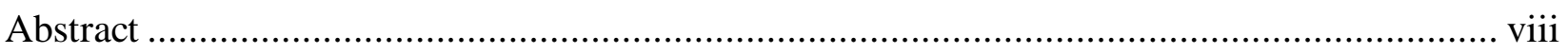

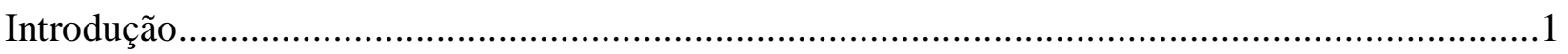

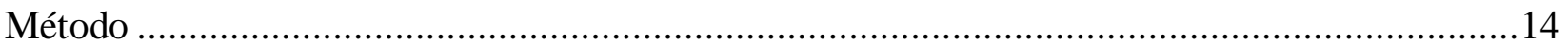

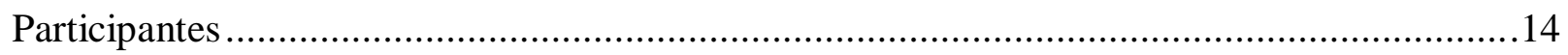

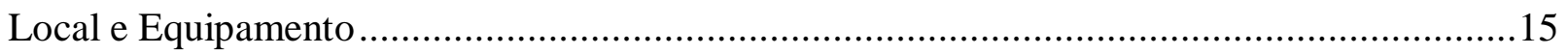

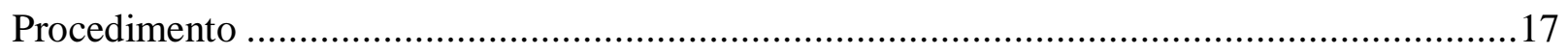

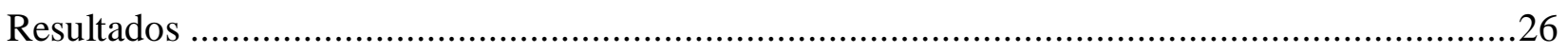

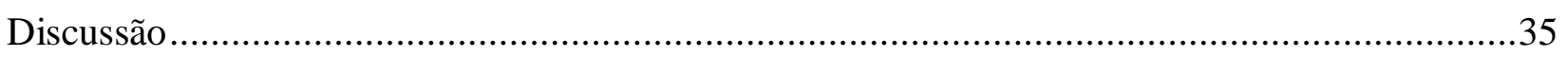

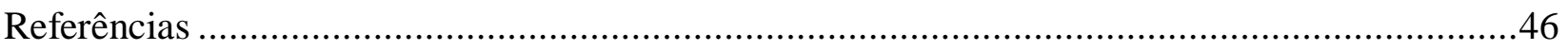

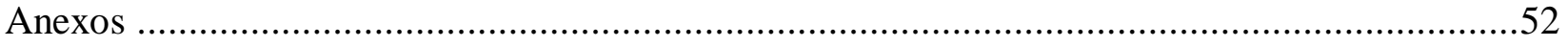




\section{Banca Examinadora}

A Banca Examinadora foi composta por:

Prof. Dra. Elenice Seixas Hanna, Universidade de Brasília, como presidente

Prof. Dr. Manoel Rodrigues dos Santos Neto, Universidade Paulista, como membro externo

Prof. Dr. Carlos Cançado, Universidade de Brasília, como membro interno

Prof. Dra. Raquel Maria de Melo, Universidade de Brasília, como membro suplente. 


\section{Agradecimentos}

Agradeço à família pelas oportunidades e pelo apoio financeiro e emocional, em especial minha mãe, Ligia Maria Pena Borges, meu pai, Marcio Nunes Cambraia e meus irmãos Maria Claudia e Marcio Rodrigo.

À minha orientadora, Prof. Dra. Elenice Seixas Hanna que tem me apoiado desde a graduação. Também a todos os membros do grupo de pesquisa, em especial à prof. Raquel Maria de Melo, às alunas Tereza Brito e Laís Calil que me ajudaram muito na fase de coleta, e à amiga Nagi Hanna Salm Costa.

Agradeço o apoio financeiro recebido pelo CNPq.

Aos amigos do Taekwondo, em especial Mestre Vinicius Avelino por ter cedido o espaço físico da academia para a realização da coleta de dados. Ao professor João Gilberto Fernandes pelo ótimo trabalho. Ao professor Roberto Brandão por tornar a prática de artes marciais tão reforçadora.

Aos membros da banca pela disponibilidade e pelas críticas fundamentais para o aprimoramento deste trabalho.

Aos participantes da pesquisa pela importante contribuição à ciência e por estarem dispostos a se deslocar até a academia quantas vezes fosse necessário.

A todos os amigos que estiveram presentes nesta fase, especialmente: Alexandre Ariel, Eliane Carvalho, Daniel Valle, David Cho, Erick Huber, Fabiana Andrade, Fabio Medeiros, Fabio Laporte, Fernanda Truite, Fernanda Werneck, Flávio Silva, Gustavo Alcântara, Kelvis Cruz, Marcus Fonseca, Maria Gabriella Costacurta, Louise Uchôa, Natasha Macedo, Paulo Cavalcanti, Paulo Peters, Pedro Melo, Renato Issao, Rodrigo Oliveira, Sarah Lopes, Tiago França e Vanessa Faria. 


\section{Lista de Figuras}

Figura 1. Setting experimental: área de treinos e lutas $\left(5 \mathrm{~m}^{2}\right)$ demarcada por fita zebrada e posicionamento das câmeras.

Figura 2. Equipamento utilizado no experimento: Protetor de tórax, protetor de canela e pé, protetor de antebraço, luvas de treino (lutas) e aparador de golpes (treinos). ...........16

Figura 3. Posições de base inicial com a perna esquerda e com a perna direita atrás. ...19

Figura 4. Tempo de treino (min) das etapas de treino do total de golpes unitários e sequências: Aquisição (A), Foco Fixo (FF), Foco Móvel (FM) e Revisão (R) para cada participante.

Figura 5. Frequência de golpes e sequências novos e ensinados emitidos pelos participantes nas fases de teste: Pré-Teste, Teste Pós-Sequência, Teste-Pós Golpes e Pós-Teste Final.

Figura 6. Porcentagem de golpes que tocaram o protetor ou o braço rente ao corpo do oponente nas fases de teste: Pré-Teste, Teste Pós-Sequência, Teste-Pós Golpes e PósTeste Final. 


\section{Lista de Tabelas}

Tabela 1. Contingência entre Comportamento e Pontos para os Lutadores . .6

Tabela 2. Características dos Participantes e Respostas ao Questionário sobre Experiência com Artes Marciais e Realização de Atividades Físicas .14

Tabela 3. Sequência de Treinos e Testes Experimentais para Cada Participante 18

Tabela 4. Definição Operacional e Figura das Movimentações Ensinadas no Treino de Movimentação 20

Tabela 5. Definição Operacional e Figura dos Golpes Ensinados na Condição Golpes 22

Tabela 6. Sequências de Golpes Ensinados na Condição Sequência .24

Tabela 7. Tempo de Treino dos Participantes para Cada Movimentação .27

Tabela 8. Tipos de Golpes "Novos" Emitidos pelos Participantes nos Pós-testes 32

Tabela 9. Tipos de Sequências "Novas” Emitidas pelos Participantes nos Pós-testes ...33 


\section{Resumo}

O Taekwondo é uma arte marcial tradicional coreana que atualmente é um esporte olímpico oficial. Nas artes marciais o repertório recombinativo é imprescindível, especialmente para contextos competitivos. Repertórios recombinativos envolvem a emergência de novas combinações de unidades previamente aprendidas. O presente estudo investigou o efeito do ensino de golpes unitários e sequências de golpes sobre o desempenho em luta simulada de Taekwondo. Constitui-se de uma replicação sistemática de pesquisa anterior sobre Karate-do. Os participantes foram jovens sem experiência em artes marciais e o procedimento envolveu o ensino e testes de golpes de Taekwondo (simulação de luta). Foi utilizado um delineamento experimental misto, em que os participantes foram expostos à uma sequência de treinos e testes que compõem duas condições experimentais. Na Condição Golpes, foram ensinados quatro golpes individuais de Taekwondo e na Condição Sequências foram ensinadas quatro sequências de três golpes. O procedimento de ensino envolveu o uso de técnicas de modelagem, modelação e instrução e foi suficiente para ensinar as habilidades programadas em até 4 h de treino. Nas lutas ocorreram golpes e sequências ensinados e novos. Sequências novas incluíram combinações de golpes aprendidos. Os resultados foram discutidos com base em estudos prévios sobre aprendizagem recombinativa e refinamentos metodológicos foram sugeridos.

Palavras-chave: Taekwondo, artes marciais, psicologia do esporte, generalização, aprendizagem recombinativa. 


\begin{abstract}
Taekwondo is a traditional martial art that is currently an official Olympic sport. In martial arts, a recombinative repertoire is indispensable, especially regarding competitive contexts. Recombinative repertoires involve the emergence of new combinations of previously learned units. The present study had the objective of investigating the effect of teaching units and sequences of attacks on performance in simulated Taekwondo sparring. It is a systematic replication of a previous research on Karate-do. Participants were young adults with no previous experience in martial arts and the procedure involved training and testing (sparring simulation) Taekwondo attacks. A mixed experimental design was used, in which participants were exposed to a sequence of training and testing that composed two conditions. In the Unit Condition participants were taught four single attacks and, in the Sequence Condition, four sequences of three attacks. Results showed that the teaching procedure involving the use of shaping, observational learning and instruction techniques was sufficient to teach the programmed skills in up to $4 \mathrm{~h}$ of training. In sparring, the occurrence of taught and new, single and in sequence attacks was observed. New sequences included combinations of taught attacks. Results were discussed based on previous studies on recombination learning and methodological refinements were proposed.
\end{abstract}

Keywords: Taekwondo, martial arts, sport psychology, generalization, recombinative learning. 
A história da Psicologia do Esporte é marcada pela publicação do primeiro estudo relacionando conceitos psicológicos (facilitação social ${ }^{1}$ ) ao desempenho esportivo (ciclistas), em 1898, pelo psicólogo social Normal Triplett. Desde então outros pesquisadores se interessaram pela área, como Coleman Griffith, considerado uma grande influência na psicologia do esporte por suas pesquisas conduzidas na Universidade de Illinois entre os anos de 1925 e 1932. Nos anos 60 surgiram as primeiras sociedades de Psicologia do Esporte como a International Society for Sport Psychology (Martin \& Thomson, 2011). Os estudos sobre esporte mais relevantes de Analistas do comportamento foram realizados somente na década seguinte. Rushall e colaboradores publicaram estudos sobre contingências de reforçamento na natação (e.g., Rushall \& Pettinger, 1969), generalização da aprendizagem para contextos competitivos (e.g., Rushall, 1970) e melhoria de desempenho utilizando pela primeira vez delineamento de sujeito único (e.g., McKenzie \& Rushall, 1974).

Estudos mais recentes em Análise do Comportamento Aplicada ao Esporte têm focado em temas como a melhoria de desempenho de atletas de alto rendimento (e.g., Reed, Critchfield, \& Martens, 2006), análise funcional de desempenho esportivo (e.g., França, 2008; Roane, 2011) e análise do comportamento esportivo utilizando a lei da igualação (e.g., Romanowich, Bourret, \& Vollmer, 2007). Esportes estudados incluem futebol americano (e.g., Stokes, Luiselli, \& Reed, 2010), rugbi (e.g., Mellalieu, Hanton, \& O’Brien, 2006) e basquete (e.g., Roane, Kelley, Trosclair, \& Hauer, 2004; Rodrigues-Neto, 2008).

A Análise do Comportamento Aplicada ao Esporte envolve o uso de princípios e técnicas da Análise do Comportamento para melhorar o desempenho e a satisfação de atletas e outros associados a esportes (técnicos, treinadores, donos de clubes esportivos)

\footnotetext{
${ }^{1}$ Facilitação social é um conceito da psicologia social que se refere à tendência de pessoas terem um desempenho melhor na presença de outras pessoas (Aronson, Wilson, \& Akert, 2002).
} 
(Martin \& Tkachuk, 2000). O presente estudo faz parte de uma nova linha de pesquisa que utiliza e avalia novas metodologias para o ensino de repertórios básicos e avalia também se os resultados dessas metodologias se generalizam para contextos competitivos. O presente trabalho buscou estudar o Taekwondo ${ }^{2}$ que, assim como outras artes marciais, tem sido um tema pouco explorado na análise do comportamento esportivo.

Taekwondo é uma arte marcial tradicional coreana. A palavra Taekwondo é composta de três partes, cada uma com um significado. "Tae" é perna, ou pé, "kwon" significa punho e "do" se refere a maneira ou disciplina. De acordo com o Estatuto da Federação Mundial de Taekwondo (WTF - World Taekwondo Federation), o objetivo do Taekwondo é treinar e fortalecer seus seguidores em corpo, mente e espírito, além de ter se desenvolvido em um esporte (World Taekwondo Federation, 2014).

Essa arte marcial tem uma história milenar nas Coréias. Ancestrais dos coreanos modernos praticavam formas primitivas da luta marcial em tribos. Na Antiguidade, o Taekwondo era praticado em batalhas territoriais e foi sofrendo mudanças. Parte dessa função foi perdida ao serem desenvolvidas armas de fogo. Porém, nas forças armadas e policiais continua a ser treinado para combate e defesa pessoal. Além disso, parece ter uma importante função social no país ao fazer parte da identidade nacional, especialmente considerando sua independência relativamente jovem, desde 1945, com o final da segunda guerra mundial (Lee \& Ricke, 2005).

No final da década de 60, o General Choi Hong Hi, presidente da Federação Internacional de Taekwondo (ITF - International Taekwondo Federation) - a primeira federação a ser criada nas Coréias - decidiu difundir a arte marcial pelo mundo. Atualmente o Taekwondo é praticado por mais de 30 milhões de pessoas e mais de 205

\footnotetext{
${ }^{2}$ Diferentes grafias romanizadas do Hangul (escrita coreana) 태권도 têm sido utilizadas, entre elas: Taekwondo, Tae Kwon Do e Taekwon-Do (Gillis, 2008).
} 
instituições pelo mundo são filiadas ao WTF (Lee \& Ricke, 2005). No Brasil, a primeira academia foi aberta em 1970 em São Paulo, pelo Mestre Sang Min Cho (Goulart \& Campos, 2011). Em 1987, a Confederação Brasileira de Taekwondo (CBTKD) foi fundada com as finalidades de representar, administrar e desenvolver o Taekwondo no Brasil, além de organizar, regulamentar e fiscalizar competições (Confederação Brasileira de Taekwondo, 2014).

O Taekwondo é praticado com vários objetivos, que recebem denominações diferenciadas. Quando o objetivo é a demonstração, existem duas modalidades: o Hosinsul, ou defesa pessoal, e o Kiopa, ou técnicas de quebramento de objetos (tábuas e tijolos). Nas modalidades que envolvem competição há o Poomse e o Kiorugui. O Poomse pode ser realizado individualmente ou em grupos e foca na topografia do comportamento, pois os movimentos são pré-determinados e devem ser executados com precisão. No Kiorugui, ou luta, o importante é a interação com o oponente, sendo imprescindível, além de condicionamento físico e agilidade, entre outros, a criatividade e imprevisibilidade na obtenção do maior número de pontos possíveis (Lopes, 2009). No presente experimento somente foi praticada a modalidade Kiorugui.

A prática do Taekwondo, apesar de ser uma arte marcial tradicional, tem se tornado cada vez mais voltada para o esporte e competição (Rios, 2005). Evidência disso é o reconhecimento do Taekwondo, desde 1988, como esporte oficial das Olimpíadas (Pimenta \& Marta, 2002).

No treinamento de Taekwondo os alunos aprendem conteúdos do Currículo Nacional de Graduação ${ }^{3}$ e realizam exames para passar para o próximo grau (Kim \& Silva, 2000). O exame exige a execução de Poomse, golpes determinados, séries de movimentações de defesa pessoal e simulação de luta (de acordo com as exigências do

\footnotetext{
${ }^{3}$ Conforme definido no Encontro Nacional de Taekwondo realizado no dia 12 de fevereiro de 1997 na cidade de Belo Horizonte (MG).
} 
grau pretendido). Para a realização de cada exame são exigidos meses e até anos de treino dos alunos. Caso o aluno atinja os critérios determinados pela Confederação, é outorgada uma faixa $(t i)$ de cor correspondente ao grau. O mais alto grau é a faixa preta, que indica maturidade e conhecimento no Taekwondo (Goulart \& Campos, 2011).

O ambiente físico dos treinos varia dependendo principalmente da academia onde ocorrem (e.g., área e material do tatame, presença de espelhos, quantidade de alunos na turma). Em uma competição, por outro lado, uma área de $8 \mathrm{~m}$ por $8 \mathrm{~m}$ é definida no manual da Federação (World Taekwondo Federation, 2012). Também estão presentes os treinadores e juízes, além de médicos e possíveis espectadores. Já nos treinos nas academias estão presentes os alunos e o professor.

O professor tem função de ensinar as habilidades do Taekwondo, comportamentos de respeito pela arte marcial $^{4}$ e entre colegas, e incentivar a assiduidade do aluno nas aulas. Os colegas também podem eventualmente auxiliar na aprendizagem dando instruções, fazendo correções dos movimentos e incentivando seus pares. O método de ensino varia entre professores. Como em qualquer esporte, a ordem de ensino e o enfoque em determinado aspecto do Taekwondo vão depender dos objetivos do professor e do atleta, bem como das características do aprendiz.

Quando alunos recebem a faixa preta já são considerados habilitados a serem professores de arte marcial. Existem algumas orientações gerais sobre o que seria considerado um bom instrutor, como dar tratamento igual a todos os alunos, desejar que os alunos se superem e dar um bom exemplo (Goulart \& Campos, 2011). Porém, o professor nem sempre programa todos os aspectos importantes para a aprendizagem e emergência de comportamentos novos (e.g., consequências imediatas individuais para

\footnotetext{
${ }^{4}$ Praticantes de Taekwondo devem seguir orientações do Juramento do Aluno ("Eu promento obedecer as regras do Taekwondo, respeitar o meu instrutor e meus superiores, nunca fazer mau uso do Taekwondo, construir um mundo mais pacífico e ser campeão da liberdade e da justiça") e observar os cinco princípios do Taekwondo: Cortesia, integridade, perseverança, autodomínio e espírito indomável (Lopes, 2009).
} 
acerto e erro, critérios de aprendizagem bem definidos para avançar para o próximo passo). A psicologia tem mostrado que alguns procedimentos são eficientes para o ensino de novos comportamentos (Catania, 1999).

O ensino por modelação (Catania, 1999) consiste em demonstrar para o aluno aquilo que se quer que ele faça. $\mathrm{O}$ instrutor faz o movimento e em seguida pede que $\mathrm{o}$ aluno repita. Uma vez capaz de emitir algumas respostas, o comportamento do aluno pode ser modelado (Pierce \& Cheney, 2004) ou dirigido por instruções (Catania, 1999). Na modelagem, o professor reforça diferencialmente aproximações sucessivas do comportamento final desejado (e.g., execução correta de determinado chute). Para tal, é importante que a consequência seja imediata e que a cada aproximação cesse as consequências que mantém o comportamento anterior (na análise do comportamento denominadas de reforçadoras). No uso de instruções, ele indica verbalmete as contingências, isto é, qual o comportamento desejado do aluno e quais as consequências de o mesmo se comportar adequadamente (ex.: "Se você levantar mais o joelho vai conseguir acertar).

Além das diferenças no ambiente físico, as contingências de uma luta de Taekwondo diferem do treino em outros aspectos importantes a serem analisados. Parte das mudanças reflete as diferenças do contexto cooperativo para o contexto competitivo (Cillo, 2003). A generalização ${ }^{5}$ do desempenho do treino para situações de competição é um dos objetivos principais da psicologia do esporte (Martin \& Thomson, 2011; Martin \& Tkachuk, 2000).

Diferentes tipos de relações podem ocorrer entre indivíduos em diferentes modalidades de Taekwondo. Tanto em treinos quanto em lutas, as contingências envolvem consequências interdependentes para o comportamento dos atletas. Nos

\footnotetext{
${ }^{5}$ Generalização, em termos simples, envolve responder de maneira similar a estímulos diferentes (Brown, 1965; Catania, 1999). No caso do Taekwondo, envolveria se comportar nas lutas de maneira similar ao que foi aprendido nos treinos.
} 
treinos, há tipicamente a cooperação, pois o comportamento de dois ou mais indivíduos é o que produzirá benefício para todos (Skinner, 1953/1981; De-Farias, 2005). Em uma luta, a situação é de competição, pois há variáveis externas comuns e intercâmbio entre os participantes e, tipicamente, um indivíduo ataca o outro (Skinner, 1953/1981). Além disso, as consequências são desiguais e excludentes. Durante uma luta, as pontuações são distribuídas desigualmente entre os participantes e, no final do intervalo ${ }^{6}$, há somente um ganhador e um perdedor (De-Farias, 2005).

As pontuações são estabelecidas conforme os critérios (contingências de reforçamento) indicados na Tabela 1 e ficam visíveis a todos no placar imediatamente (World Taekwondo Federation, 2012). As contingências são ditadas por regras que podem ser descritas como relações de contingência do tipo: Se o lutador que ataca emitir um chute ou soco no protetor de tórax de seu oponente, então receberá um ponto no placar; se o chute for na cabeça, então receberá três pontos; chutes rodados - ou seja, que envolvem rodar o próprio corpo em, pelo menos, $180^{\circ}$ - acrescentam outro ponto ao placar de quem ataca.

Tabela 1.

Contingência entre comportamento e pontos para ambos lutadores.

\begin{tabular}{lcc}
\hline \multicolumn{1}{c}{ Comportamento } & \multicolumn{2}{c}{ Consequências } \\
\cline { 2 - 3 } & Para quem Ataca & Para o Oponente \\
\hline Chute ou soco no protetor de tórax & 1 ponto & 0 ponto \\
Chute rodado no protetor de tórax & 2 pontos & 0 ponto \\
Chute na cabeça & 3 pontos & 0 ponto \\
Chute rodado na cabeça & 4 pontos & 0 ponto \\
2 Kyong-go & 0 ponto & 1 ponto \\
Gam-jeom & 0 ponto & 1 ponto \\
\hline
\end{tabular}

\footnotetext{
${ }^{6}$ A duração oficial de uma luta é de três rounds (etapas) de 2 mins com intervalos de 1 min entre rounds. Em caso de empate, é iniciado um quarto round de 2 mins de "morte súbita", ou seja, quem fizer pelo menos um ponto primeiro ganha a luta (World Taekwondo Federation, 2012).
} 
O protetor de tórax do oponente é estímulo discriminativo ${ }^{7}$ para chutes simples e rodados e socos. A cabeça, por outro lado, somente evoca chutes, pois socos são penalizados. Outras ações proibidas para o atacante incluem: xingamentos, ataques em áreas proibidas ou com partes do corpo proibidas e sair do tatame. Quando as ações são consideradas "leves", o juíz indica uma Kyong-go, ou falta de aviso; quando são "graves", indica uma Gam-jeom, ou falta de dedução. Duas faltas de aviso correspondem a uma falta de dedução e a consequência é que o oponente ganha um ponto no placar (World Taekwondo Federation, 2012).

Nas artes marciais em geral, um repertório criativo é imprescindível, especialmente para situações de competição. Ao emitir sequências de golpes diferentes, o lutador está em vantagem, pois se torna imprevisível. Além das habilidades necessárias para executar cada golpe com sucesso, a capacidade de combinar esses golpes em uma sequência tem a dupla função de inibir possíveis golpes do adversário e aumentar a probabilidade de marcar pontos na luta.

O comportamento criativo, para a Análise do Comportamento, surge por meio de um processo similar à seleção natural: envolve variações inéditas de comportamentos, selecionadas pelas suas consequências reforçadoras (Barbosa, 2003; Catania, 2001; Skinner, 1981). Estudos das áreas de insight e aprendizagem recombinativa visam explicar comportamentos novos não diretamente ensinados, mas relacionados à aprendizagem anterior de diferentes repertórios que podem ser combinados ou recombinados em determinadas situações problema.

Wolfgang Köhler publicou o que é considerado o primeiro trabalho de insight: The Mentality of Apes (1925). A pesquisa teve o objetivo de estudar o comportamento de chimpanzés na ilha de Tenerife, Espanha, para verificar se exibiriam

\footnotetext{
${ }^{7}$ Estímulo discriminativo é um estímulo presente no ambiente que evoca determinado comportamento e sinaliza a presença da consequência reforçadora (Pierce \& Cheney, 2004).
} 
comportamentos de inteligência e insight assim como seres humanos. Para tal, Köhler colocou os símios em diferentes situações problema que envolviam o uso de ferramentas para conseguir comida que estava fora do alcance direto.

Köhler (1925) faz uma descrição topográfica dos comportamentos dos chimpanzés, sendo que todos conseguiam solucionar os problemas (chegando ao alimento), mas alguns com mais dificuldade que os outros. O termo insight foi cunhado por Köhler para descrever um processo de compreensão espontânea de problemas, em que uma solução súbita emerge em situações novas após uma aparente confusão inicial. O termo foi utilizado posteriormente também por outras abordagens da Psicologia, como a Psicanálise e a Psicologia Analítica (Schultz \& Schultz, 2009).

Analistas do Comportamento iniciaram estudos na área de insight a partir de Epstein e colaboradores (Epstein, Kirshnit, Lanza \& Rubin, 1984; Epstein, 1985, 1987). Apesar das importantes contribuições de Köhler para a psicologia, ao trazer para debate questões sobre princípios envolvidos na aprendizagem e emergência de comportamentos novos, os estudos descritos foram criticados por falta de controle da história pré-experimental dos animais (Epstein e cols., 1984; Epstein, 1985, 1987).

Epstein e cols. (1984) buscaram replicar os achados de Köhler estudando os antecedentes e determinantes de desempenhos de resolução de problemasem pombos. Para controlar os antecedentes, os experimentadores ensinaram aos pombos três comportamentos. Os testes consistiram em colocar o pombo em uma caixa experimental com uma caixa no chão e uma banana de plástico no alto. Os pombos demonstraram comportamentos característicos de insight - uma aparente confusão ao serem colocados na caixa (andar e olhar da caixa para a banana) e, repentinamente, (1) empurraram a caixa para de baixo da banana, (2) subiram na caixa e (3) bicaram a banana. Somente os pombos que aprenderam todos os comportamentos foram capazes de "solucionar" o 
teste. Pombos que aprenderam apenas um ou dois comportamentos (e.g., empurrar a caixa, bicar a banana, mas não subir na caixa), não tiveram os mesmos resultados. Os autores concluíram que foram replicados os achados com chimpanzés, a resolução de problema pelos pombos foi "súbita, direta e contínua" (p.62). O experimento demonstrou a importância da história de aprendizagem para a emergência de repertórios novos.

Experimentos posteriores com ratos (Delage \& Carvalho Neto, 2010) e macacos prego (Neves Filho, 2010; Delage, 2011) corroboraram os achados dos experimentos descritos anteriormente. Os resultados demonstraram que insight decreve um processo de combinação de respostas treinadas anteriormente; ou seja, em uma situação nova, comportamentos previamente aprendidos emergem como uma sequência que produz um reforço final, no caso, alimento. Esses resultados indicam que a construção de um repertório a partir do ensino direto de determinadas habilidades determina a emergência de comportamentos encadeados em uma situação nova. Esta noção poderia ser útil para maximizar o desempenho de um aprendiz na situação de luta de Taekwondo. A aprendizagem de cada golpe seria necessária para a emergência de um repertório com grande probabilidade de ser reforçado (sequências criativas, ou seja, novas e variadas).

O segundo tema de pesquisa relacionado à aprendizagem de novas sequências comportamentais é "generalização recombinativa". O termo foi cunhado por Goldstein (1983) a partir de estudos sobre o ensino de palavras com o objetivo de mostrar condições necessárias para o desenvolvimento de linguagem gerativa. De acordo com o autor, pode ser definido como "responder diferencial a novas combinações de componentes de estímulos que tenham sido previamente incluídos em outros contextos de estímulos" (p. 281). Em outras palavras, o termo descreve novas combinações de 
unidades previamente aprendidas. Elementos de estímulos componentes de relações aprendidas são recombinados em novas configurações e cada componente continua a exercer controle preciso e apropriado sobre o componente correspondente das respostas. Em termos de lingugagem, unidades como letras, sílabas e palavras podem ser combinadas e recombinadas, de acordo com regras gramaticais, criando unidades funcionais maiores (Goldstein, 1983, 1993). De forma análoga, golpes de Taekwondo poderiam ser combinados em sequências, criando unidades maiores.

A aprendizagem recombinativa ${ }^{8}$ tem sido demonstrada em uma série de estudos com palavras da língua portuguesa (e.g., de Rose, de Souza, \& Hanna, 1996; Serejo, Hanna, de Souza, \& de Rose, 2007), pseudopalavras (e.g., Hanna, Karino, Araújo, \& de Souza, 2010; Hanna, Kohlsdorf, Quinteiro, Fava, de Souza, \& de Rose, 2008) e partituras musicais (e.g., Batitucci, 2007; Huber, 2010), quando sujeitos foram capazes de responder diferencialmente a novos estímulos formados pela combinação de elementos dos estímulos ensinados.

Leitura generalizada é extremamente importante para o processo de alfabetização. Por exemplo, Hanna e cols. (2008) criaram um sistema linguístico em miniatura para intercalar o ensino condicional de palavras e sílabas com testes de leitura de palavras novas, formadas pela recombinação de elementos das palavras ensinadas. Resultados desse tipo de pesquisa têm mostrado que o repertório recombinativo se desenvolve a partir do ensino de unidades menores (sílabas ou grafemas/fonemas) em conjunto com o ensino de palavras, como unidades semânticas (e.g., Hanna, Karino, Araújo, \& de Souza, 2010). O repertório novo, ou recombinativo, na leitura depende de variáveis como a quantidade de treino (e.g., Serejo, Hanna, de Souza, \& de Rose, 2007) e o ensino com múltiplos exemplares (e.g., Quinteiro, 2003 ), nos quais varia a posição

\footnotetext{
${ }^{8}$ Apesar de usar o termo generalização, o próprio Goldstein (1993) reconhece que é infeliz, pois na verdade o comportamento novo envolve discriminação das partes de um estímulo composto.
} 
das sílabas e letras dentro das palavras (para revisão, ver de Souza, Hanna, Albuquerque, \& Hübner, 2014).

Experimentos de insight e de aprendizagem recombinativa são estudos sobre a emergência de novas cadeias comportamentais, mas que analisam contextos diferentes. Em primeiro lugar, enquanto experimentos de insight usaram animais não humanos como sujeitos, experimentos de aprendizagem recombinativa têm usado principalmente participantes humanos por tradicionalmente se interessar pela questão na linguagem gerativa. Apesar de ambos planejarem uma história de aprendizagem para os sujeitos, a situação "nova" em que os mesmos devem se comportar difere.

Experimentos sobre leitura textual (de Souza e cols., 2014) apresentam testes nos quais estão presentes estímulos discriminativos (e.g., sílabas escritas, BO e LO) que correspondem ponto-a-ponto com cada elemento da cadeia comportamental (e.g., verbalizar "BOLO”). Nos experimentos de Epstein e cols. (1984) e Epstein (1985, 1987) o ambiente não sinaliza claramente um estímulo discriminativo para cada resposta na cadeia, nem a ordem das respostas. Os experimentos sobre leitura recombinativa têm desenvolvido sua metodologia e obtido controle experimental no sentido de planejar a situação nova e explicitar como foi criada, ou seja, o que tem em comum com a situação de treino e o que é novidade no teste.

Pesquisas na área de aprendizagem recombinativa tem mostrado que ensinos de unidades menores (que neste estudo são golpes), em conjunto com ensino de unidades maiores (sequências de golpes), aumentam a probabilidade de emergirem repertórios não ensinados diretamente (sequências novas). Porém, assim como repertórios de leitura musical têm particularidades com relação à leitura de palavras (e.g., Batitucci, 2007; Huber, 2010), repertórios esportivos têm diferenças, ainda a serem estudadas sistematicamente. 
A formação de repertórios recombinativos foi estudada por França (2013) em uma pesquisa com artes marciais, na área do esporte e do exercício. O estudo buscou, na literatura sobre solução de problemas e principalmente aprendizagem recombinativa, uma metodologia para ajudar na compreensão de desenvolvimento de repertórios novos em lutas de Karate-do. Os participantes foram jovens de 18 a 30 anos sem experiência na prática de artes marciais que realizaram duas condições experimentais com etapas de ensino de golpes unitários ou sequências de golpes de Karate-do e testes em situação de luta simulada para avaliar o efeito das condições de ensino. Na Condição Elemento foram ensinados seis golpes que consistiram de socos e chutes com os membros direiro e esquerdo. Na Condição Sequência, o participante aprendia quatro sequências de golpes. Os resultados mostraram que aproximadamente quatro horas de treino com os procedimentos de ensino (modelagem, modelação e instrução) foram suficientes para os participantes aprenderem com poucos erros os golpes e as sequências programadas. Nos testes de luta simulada, realizados após cada condição, os participantes utilizaram os golpes e sequências ensinadas e também sequências novas. Porém, não foi observado efeito sistemático das diferentes condições experimentais (Elemento e Sequência) sobre o desempenho durante as lutas.

O presente estudo replicou França (2013) realizando algumas modificações metodológicas. Em primeiro lugar, foi acrescentado um pré-treino de movimentações básicas, para que o participante soubesse se locomover pelo tatame e mantivesse a distância adequada do oponente. A quantidade de golpes ensinados foi reduzida (de seis para quatro) para se adequar às características do Taekwondo: (1) Somente foram ensinados golpes na região do tórax (para praticantes que ainda não obtiveram a faixa preta é vedado chutes à cabeça em lutas); (2) Predominantemente chutes; e (3) A dificuldade dos golpes variou (muitos envolvem rotação do corpo). 
No presente estudo, a quantidade de treino foi padronizada nas duas condições experimentais - quatro golpes e quatro sequências, com igual tempo mínimo de treino em todas as etapas. França (2013) ensinou seis golpes e quatro sequências e definiu tempos mínimos para etapas de ensino diferentes. Os testes de luta simulada, que em França (2013) envolviam golpes e sequências do instrutor diferentes dos ensinados, passaram, neste estudo, a incluir somente golpes que fazem parte do treino, para evitar aprendizagem por imitação de comportamentos novos do instrutor durante a situação de luta. Somente o teste final de luta incluiu novos golpes, buscando maior semelhaça com uma situação de luta real. A duração dos testes do presente estudo, diferentemente do estudo anterior de Karate-do, em que as lutas variaram de tempo (2 min Teste com Adversário e 90 s Teste de Generalização), foi igual para facilitar a análise e comparação dos resultados entre os testes. Por fim, no estudo de França o experimentador atuou também como instrutor, enquanto que no presente estudo um instrutor sem envolvimento com a pesquisa foi treinado pelo experimentador para realizar as sessões de ensino e de teste.

O presente estudo, portanto, investigou o efeito do ensino de golpes unitários e sequências de golpes de Taekwondo sobre o desempenho em lutas simuladas. Os objetivos específicos incluíram: (1) Identificar e definir golpes e sequências do Taekwondo para serem ensinados; (2) Avaliar se o uso de modelagem, modelação e instrução por um instrutor treinado a utilizar esses procedimentos (e com supervisão do experimentador durante a coleta) foi suficiente para ensinar o conjunto de habilidades;

(3) Comparar o treino de golpes unitários com o de sequências de golpes; e (4) Comparar o efeito de ensino de golpes unitários e sequências sobre o desempenho em situação de luta simulada. 


\section{Método}

\section{Participantes}

Participaram do estudo oito jovens com idades entre 18 e 28 anos $^{9}$. Para balancear possíveis efeitos de sexo, foram selecionados duas mulheres e dois homens para cada condição experimental. A pesquisa foi realizada com pessoas sem experiência anterior com a prática do Taekwondo, de outras artes marciais de impacto (como Karate-Do, Kung Fu - Wushu e Sanshou, Krav Magá, Ninjutsu e Wing Tsun), ou esportes de luta como o Boxe e o Kickboxe. Essas informações foram obtidas a partir de um questionário aplicado no início do estudo (Anexo A). A Tabela 2 mostra os dados dos participantes escolhidos para a pesquisa.

Tabela 2

Características dos Participantes e Respostas ao Questionário sobre Experiência com Artes Marciais e Realização de Atividades Físicas

\begin{tabular}{|c|c|c|c|c|c|c|}
\hline \multirow{2}{*}{ Participante } & \multirow{2}{*}{ Sexo } & \multirow{2}{*}{ Idade } & \multicolumn{3}{|c|}{ Experiência com Arte Marcial } & \multirow{2}{*}{ Atividade Física } \\
\hline & & & $\mathrm{TV}$ & Filme & Videogame & \\
\hline $\mathrm{P} 1$ & M & 18 & não & $\operatorname{sim}$ & $\operatorname{sim}$ & Vôlei, atletismo \\
\hline $\mathrm{P} 2$ & $\mathrm{~F}$ & 18 & não & não & não & Pilates \\
\hline P3 & M & 28 & $\operatorname{sim}$ & $\operatorname{sim}$ & não & Futebol, musculação \\
\hline P4 & $\mathrm{F}$ & 22 & não & não & $\operatorname{sim}$ & Academia \\
\hline P5 & $\mathrm{F}$ & 25 & $\operatorname{sim}$ & não & $\operatorname{sim}$ & $\begin{array}{l}\text { Futebol, vôlei, } \\
\text { academia }\end{array}$ \\
\hline P6 & $\mathrm{F}$ & 27 & não & não & não & Corrida, musculação \\
\hline P7 & M & 23 & não & não & não & $\begin{array}{c}\text { Musculação, natação, } \\
\text { ioga }\end{array}$ \\
\hline P8 & M & 22 & $\operatorname{sim}$ & $\operatorname{sim}$ & $\operatorname{sim}$ & $\begin{array}{c}\text { Futebol, musculação, } \\
\text { natação }\end{array}$ \\
\hline
\end{tabular}

\footnotetext{
${ }^{9}$ Os dados de dois participantes não foram incluídos por erros ocorridos durante a coleta. Por exemplo, o instrutor consequenciou alguns erros desses participantes com "não é assim", "não está correto", quando deveria apenas fazer a correção. Também houve alguns erros do instrutor nas lutas, como golpes unitários executados com o membro errado (e.g., direito em vez de esquerdo) e sequências diferentes das planejadas.
} 
Os participantes foram consultados sobre o interesse em participar da pesquisa e informados sobre o objetivo geral da pesquisa. Em primeiro lugar, responderam o Questionário de Prontidão para Atividade Física (PAR-Q - Physical Activity Readiness Questionnaire) (Anexo D) e só foram selecionados aqueles que responderam "não" para todas as perguntas, indicando não ter restrições médicas para a prática de atividades físicas. Também leram e assinaram o Termo de Consentimento Livre e Esclarecido (em conformidade com a Resolução 196/96) (Anexo B) e o Termo de Autorização para Utilização de Imagem e Som de Voz para Fins de Pesquisa (Anexo C).

O projeto de pesquisa foi aprovado pelo Comitê de Ética em Pesquisa da Faculdade de Ciências Humanas da Universidade de Brasília (parecer $n^{\circ}$ 866.575). Após o término da coleta de dados os participantes receberam o direito de, caso fosse de seu interesse, dar continuidade ao treinamentos na academia de Taekwondo por duas semanas, sem custo.

\section{Local e Equipamento}

A coleta de dados foi realizada no espaço físico de uma academia de Taekwondo no bairro Asa Sul de Brasília (Figura 1). Uma área de 5m x 5m foi delimitada no tatame com uma faixa zebrada fixada no chão com fita adesiva, dentro da qual foram realizadas as sessões. Uma das paredes era revestida de espelho.

Foram utilizados os equipamentos de proteção básicos de Taekwondo, providenciados pelo experimentador: protetor de tórax, protetores de antebraço, luvas e protetores de canela (Figura 2). O protetor de cabeça não foi necessário devido a todos os golpes ensinados e permitidos no estudo serem na área do tórax. Foi explicado para os participantes que deveriam comparecer à sessão com roupas propícias para a realização de exercício físico. O instrutor utilizava uniforme do 
Taekwondo (dobok). Também foi utilizado um escudo pequeno como aparador de golpes.

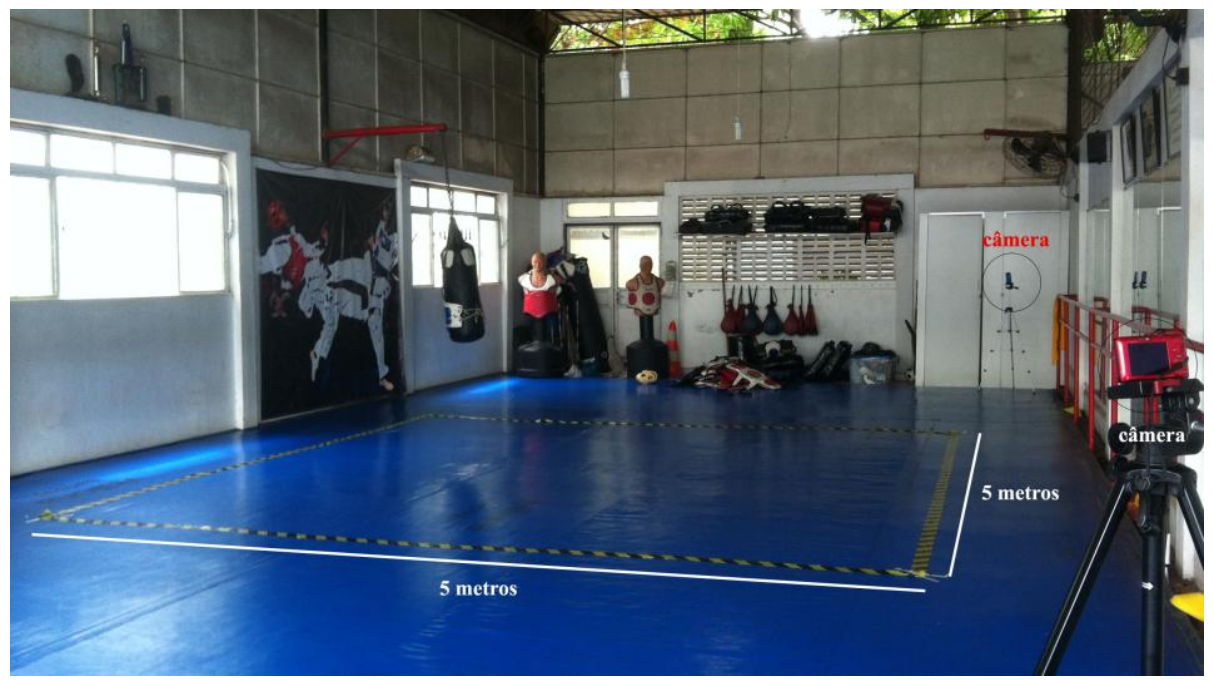

Figura 1. Setting experimental: área de treinos e lutas $\left(5 \mathrm{~m}^{2}\right)$ demarcada por fita zebrada e posicionamento das câmeras.

Todas as sessões foram filmadas com duas câmeras digitais de vídeo apoiadas em tripé para registro e análise dos golpes: uma Kodak play sport e uma Canon Powershot SD780 IS. Também foi utilizado um cronômetro digital para registro do tempo das etapas do experimento.

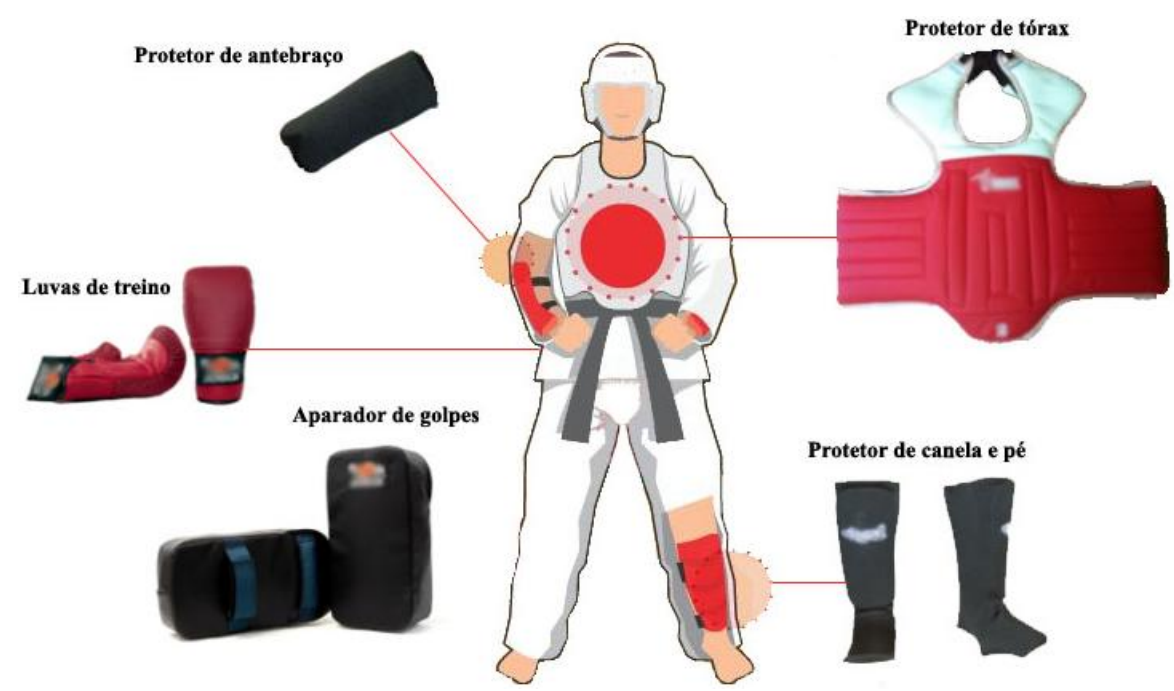

Figura 2. Equipamento utilizado no experimento: Protetor de tórax, protetor de canela e pé, protetor de antebraço, luvas de treino (lutas) e aparador de golpes (treinos). Adaptado de: http://super.abril.com.br/multimidia/info_494258.shtml. 


\section{Procedimento}

Foi utilizado um delineamento misto, em que todos os participantes foram expostos a duas condições experimentais com balanceamento da ordem de apresentação das condições para cada quatro participantes. Metade dos participantes passou pela Condição Golpes seguida pela Condição Sequências e a outra metade passou pelas condições em ordem inversa. Os participantes foram distribuídos aleatoriamente entre os dois grupos.

O instrutor foi um atleta graduado com faixa-preta de Taekwondo e experiência prévia de ensino de artes marciais, treinado especialmente para realizar as etapas de ensino e avaliação, tomando os cuidados necessários para garantir a integridade dos participantes. O treinamento consistiu em leitura do projeto por parte do instrutor seguido de uma aula expositiva sobre os objetivos da pesquisa e detalhes do procedimento. Depois o instrutor praticou as etapas com a experimentadora e, finalmente, realizou o procedimento com um participante piloto que não tinha experiência em artes marciais (mas era ciente de detalhes do experimento) sem conhecimento de que não se tratava de um participante de fato. Durante a atuação do instrutor com o participante piloto, a experimentadora observava a interação e fornecia dicas ao instrutor quando o procedimento não era seguido.

Os participantes realizaram sessões com duração de, no máximo, 60 minutos cada. As sessões eram marcadas com pelo menos um dia de intervalo buscando a recuperação física dos participantes.

No início de cada sessão experimental foram realizados 10 a 15 minutos de alongamento e aquecimento para reduzir o risco de lesões físicas. Assim que aquecidos, os participantes fizeram o Pré-teste de Luta Simulada e o Treino de Movimentação no tatame. Em seguida, foram realizadas as duas condições experimentais com cada 
participante, cada uma consistindo do Treino de Golpes ou Sequências de Taekwondo seguido pelo Pós-Teste de Luta Simulada daquele treino. Quatro participantes (P1, P2, P3 e P4) iniciaram na Condição Sequências, aprendendo quatro golpes unitários na etapa de ensino, e em seguida passaram pela Condição Golpes, aprendendo quatro sequências de três golpes cada. Os outros quatro participantes (P5, P6, P7 e P8) realizaram as condições na ordem inversa. No final do estudo, houve um Pós-teste de Luta Final, mais próximo de uma situação de luta real. A Tabela 3 ilustra a sequência de testes e treinos pelas quais cada participante passou.

Tabela 3

Sequência de Treinos e Testes Experimentais para cada Participante

\begin{tabular}{ccc}
\hline Sequência & $\begin{array}{c}\text { Grupo Sequências-Golpes } \\
(\text { P1 a P4) }\end{array}$ & $\begin{array}{c}\text { Grupo Golpes-Sequências } \\
\text { (P5 a P8) }\end{array}$ \\
\hline 1 & Pré-teste de Luta Simulada & Pré-teste de Luta Simulada \\
2 & Treino de Movimentação & Treino de Movimentação \\
3 & Treino de Golpes & Treino de Sequências \\
4 & Teste de Luta Simulada & Teste de Luta Simulada \\
5 & Treino de Sequências & Treino de Golpes \\
7 & Teste de Luta Simulada & Teste de Luta Simulada \\
8 & Teste Final de Luta Simulada & Teste Final de Luta Simulada \\
\hline
\end{tabular}

Treino de movimentação. Neste treino, foram ensinadas algumas movimentações básicas do Taekwondo. O objetivo foi permitir que os participantes pudessem se movimentar livremente no tatame de forma correta.

Em um primeiro momento, foi demonstrada a base do Taekwondo, na qual o participante se coloca em posição inicial para realizar qualquer golpe. Essa posição inicial pode ser tanto com a perna direita atrás, quanto com a perna esquerda atrás, pois no Taekwondo é desejável que os lutadores realizem todos os golpes tanto com a perna direita quanto com a esquerda (Figura 3). 

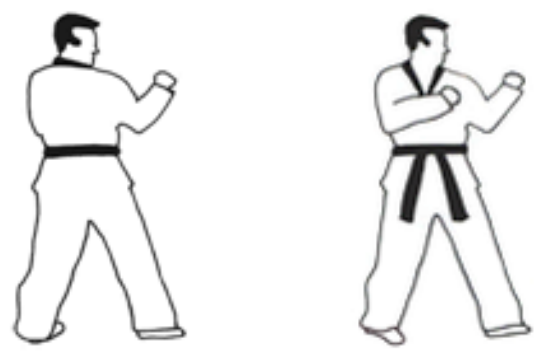

Figura 3. Posições de base inicial com a perna esquerda e com a perna direita atrás.

O instrutor então demonstrava a movimentação e pedia que o participante repetisse. Os movimentos ensinados permitiam que o participante se movesse para frente, para trás e trocasse de base no mesmo lugar (troca de pernas sem avançar nem recuar) (Tabela 4). O critério de aprendizagem era não haver dois erros consecutivos em um bloco de 30 segundos, desde que fosse realizado o tempo mínimo estabelecido para cada etapa. Nesse treino o participante deveria fazer, no mínimo, 1 minuto de treino para passar para o treino seguinte. O critério foi o mesmo para todos os treinos do experimento.

A consequência para a execução correta das movimentações era o instrutor fazendo elogios verbais (ex: "Isso", “bom”, "beleza"). O instrutor elogiava o participante toda vez que um tipo de movimentação era finalizado com sucesso, indicando que o mesmo estava progredindo. Caso o participante executasse o movimento incorretamente, o instrutor enfatizava verbalmente a característica do movimento que o aluno precisava melhorar (ex: "Junte mais as pernas quando fizer a troca”) (instrução). Quando necessário, o instrutor mostrava novamente o movimento (modelação). As consequências eram as mesmas para todas as fases de treino do experimento. Além de estabelecer as consequências, o instrutor decidia no momento se deveria haver alguma consequência (de acerto ou erro) e qual seria (elogio, instrução, modelação). 
Tabela 4

Definição Operacional e Figura das Movimentações Ensinadas no Treino de Movimentação

Movimentação e Definição Operacional
1. Troca de base no mesmo lugar:
posição de base com a perna direita
atrás, trocar as pernas de lugar ao
mesmo tempo, invertendo a base para
ficar com a perna esquerda atrás na
posição em que estava a direita. Repetir
O movimento, voltando para a posição
inicial.
2. Troca de base pra frente: Na
posição de base com a perna direita
atrás, dar um passo para frente com a
perna direita, de modo que a mesma
passe a ficar na frente e a perna
esqueda atrás, mantendo a posição de
base. Repetir colocando a perna
esquerda na frente.
3. Troca de base pra trás: Na posição
de base com a perna direita atrás, dar
um passo para trás com a perna
esquerda, de modo que a mesma passe
a ficar atrás e a perna direita na frente,
mantendo a posição de base. Repetir
colocando a perna direita atrás.

Finalmente, o instrutor pedia que o participante se posicionasse à sua frente $\mathrm{e}$

fizesse os movimentos opostos com relação ao instrutor, por exemplo, quando o

instrutor ia para a frente, o participante deveria ir para trás. Esse exercício teve como

objetivo permitir que o participante aprendesse a se movimentar pelo tatame com

fluidez e rapidez, a uma distância adequada de outra pessoa, conforme numa luta de

Taekwondo. Apenas nesse exercício o critério de aprendizagem era nenhum erro em 30

s, para que a distância entre instrutor e participante sempre se mantivesse igual.

Treino de golpes unitários. A fase de treino consistiu em três etapas de ensino:

Aquisição, Foco Fixo e Foco Móvel. As três etapas foram utilizadas para ensinar cada 
um dos quatro golpes escolhidos para ensino. Nesse treino o participante deveria fazer, no mínimo, $30 \mathrm{~s}$ de treino com cada golpe para passar para a etapa seguinte.

Foram escolhidos quatro golpes de Taekwondo (um soco e três chutes), de acordo com três critérios: (1) baixo nível de dificuldade; (2) diferença entre os golpes, para facilitar a observação dos vídeos (um soco, um chute de frente, um chute de lado e um chute de costas); (3) área de impacto no oponente (somente na altura do protetor de tórax); e (4) todos os chutes com a área inferior (sola) do pé. Cada golpe foi então definido operacionalmente para este estudo (Tabela 5).

Foram ensinados três tipos de chute e apenas um soco, pois no Taekwondo a utilização das pernas é muito mais frequente do que dos braços para desferir golpes. Foi ensinado um golpe por vez até que os critérios de aprendizagem dos três passos de ensino fossem atingidos. Metade dos golpes eram realizados com a perna direita e a outra metade com a perna esquerda. Todos terminavam com a base invertida, ou seja, se na posição inicial a perna direita estava atrás, na final a esquerda ficava atrás e viceversa.

Na etapa de Aquisição, o participante deveria primeiro imitar corretamente o golpe que o instrutor fazia (modelação). A instrução dada foi: “Agora vou te ensinar alguns golpes do Taekwondo. Observe como eu faço e tente fazer igual". A execução correta dava início à segunda parte da etapa de Aquisição, na qual o participante deveria executar sozinho o golpe ensinado. Quando esse passo era completado, o instrutor dava início à etapa de Foco Fixo. Nesta etapa, o instrutor utilizava um aparador de golpes e pedia para o participante executar o mesmo golpe finalizando com o toque no alvo. Em seguida, era realizado a etapa de Foco Móvel, em que o participante deveria realizar o golpe ensinado para atingir o alvo que se deslocava para uma posição diferente no 
tatame a cada tentativa. Assim, o participante deveria se movimentar para frente, para

trás e/ou para os lados antes de executar o golpe.

Tabela 5

\section{Definição Operacional e Figura dos Golpes Ensinados na Condição Golpes}

\section{Golpe e Definição Operacional} Imagem

1. Ap tchagui: Na posição de base com a perna esquerda atrás, levantar o joelho da perna esquerda e chutar na altura do abdômen com um movimento para cima. A zona de impacto é a sola do pé próxima aos dedos. O movimento termina com a base trocada (perna direita atrás).
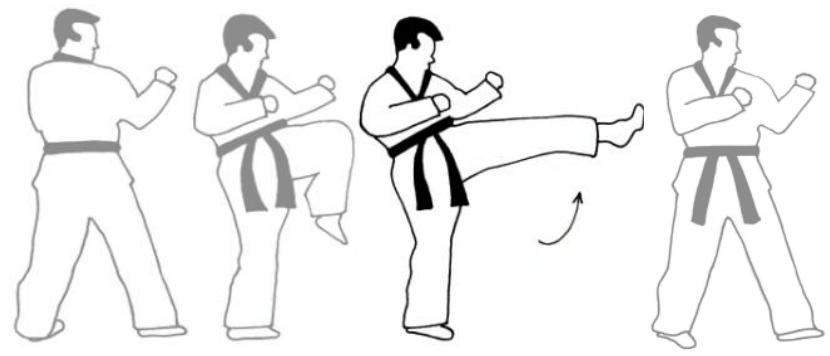

2. Iop tchagui : Na posição de base com a perna direita atrás, levantar o joelho da perna direita, abaixar levemente o tronco e chutar de lado, com um movimento de empurrar, na altura do abdômem. A zona de impacto é a faca do pé. O movimento termina com a base trocada (perna esquerda atrás).

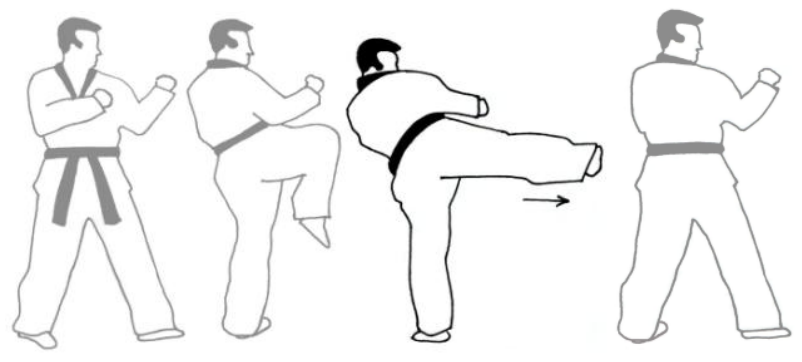

3. Jirugui: Na posição de base com a perna esquerda atrás, movimentar para frente o punho esquerdo dando um soco na altura do abdômen; ao mesmo tempo, trocar de base (perna direita atrás).

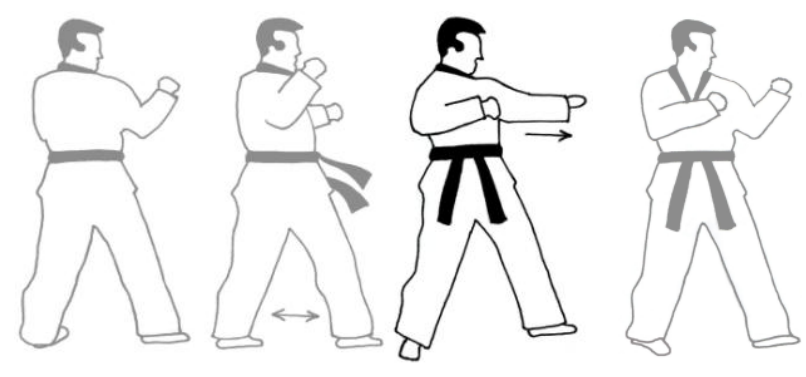

4. Ti tchagui: Na posição de base com a perna direita atrás, virar a orientação do corpo $180^{\circ}$ em sentido horário e chutar com a perna direita para trás, na altura do abdômen, como um coice. A zona de impacto é o calcanhar. O movimento termina com a base trocada (perna
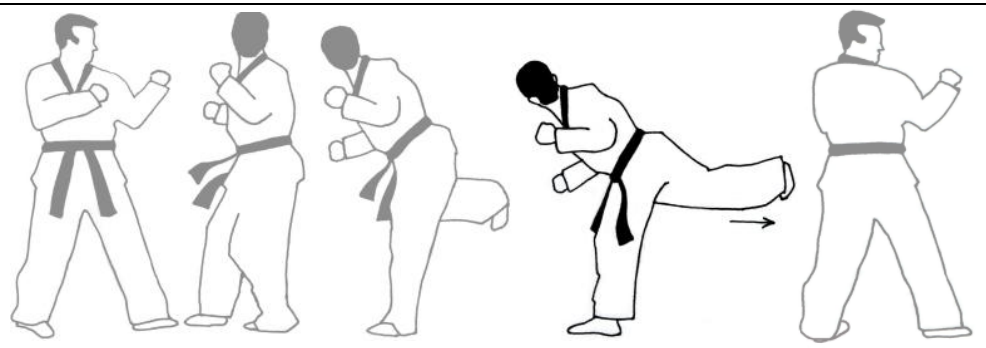
esquerda atrás).

Nota. Os chutes estão em seus nomes coreanos transcritos para o português, que descrevem brevemente a topografia do chute, sendo que a palavra "tchagui" se repete em todos, pois corresponde a "chute" e "jirugui" se refere a "soco".

Depois de passar por todas as etapas de treino com cada um dos quatro golpes, o participante passava novamente por todas as fases mais duas vezes para cada golpe, em 
ordem variada. $\mathrm{O}$ objetivo dessa repetição foi equiparar a quantidade de treino $(1,5 \mathrm{~min}$ de treino por golpe por etapa, no mínimo) entre as duas condições experimentais. No final dessa condição era encerrada a sessão. A sessão também poderia ser encerrada antes do final, caso o participante não terminasse ao completar 60 minutos de treino ou, ainda, caso demonstrasse cansaço ou queda no desempenho. Nesses casos o treino era retomado na sessão seguinte.

As consequências para acerto e erro, bem como o critério de aprendizagem foram os mesmos para todos os passos. No começo da Aquisição, a cada execução correta o instrutor fazia elogios verbais. Quando começava a contar o tempo, as indicações de acerto se tornavam menos frequentes. $\mathrm{O}$ instrutor elogiava o participante toda vez que uma etapa de treino era terminada com sucesso, indicando que o mesmo estava progredindo. Caso o participante executasse o movimento incorretamente, o instrutor enfatizava verbalmente a característica do movimento que o aluno precisava melhorar (ex: "Levante um pouco mais o joelho"). Quando ocorriam dois erros em um bloco de $30 \mathrm{~s}$, o instrutor mostrava novamente o golpe.

Treino de sequências de golpes. Quatro sequências compostas por três golpes diferentes dentre os quatro utilizados no presente estudo foram escolhidas para serem ensinadas diretamente na Condição Sequências (Tabela 6). A posição dos golpes nas sequências garantiu que cada elemento ocorresse no início, no meio e no final das sequências. Os golpes escolhidos para compor determinada sequência nunca se repetem dentro da mesma sequência.

O ensino das sequências teve as mesmas etapas que o treino de golpes. As consequências para acerto e erro, o tempo mínimo de treino (1,5 min), bem como o critério de aprendizagem também foram os mesmos. 


\section{Tabela 6}

Sequências de Golpes Ensinados na Condição Sequências.

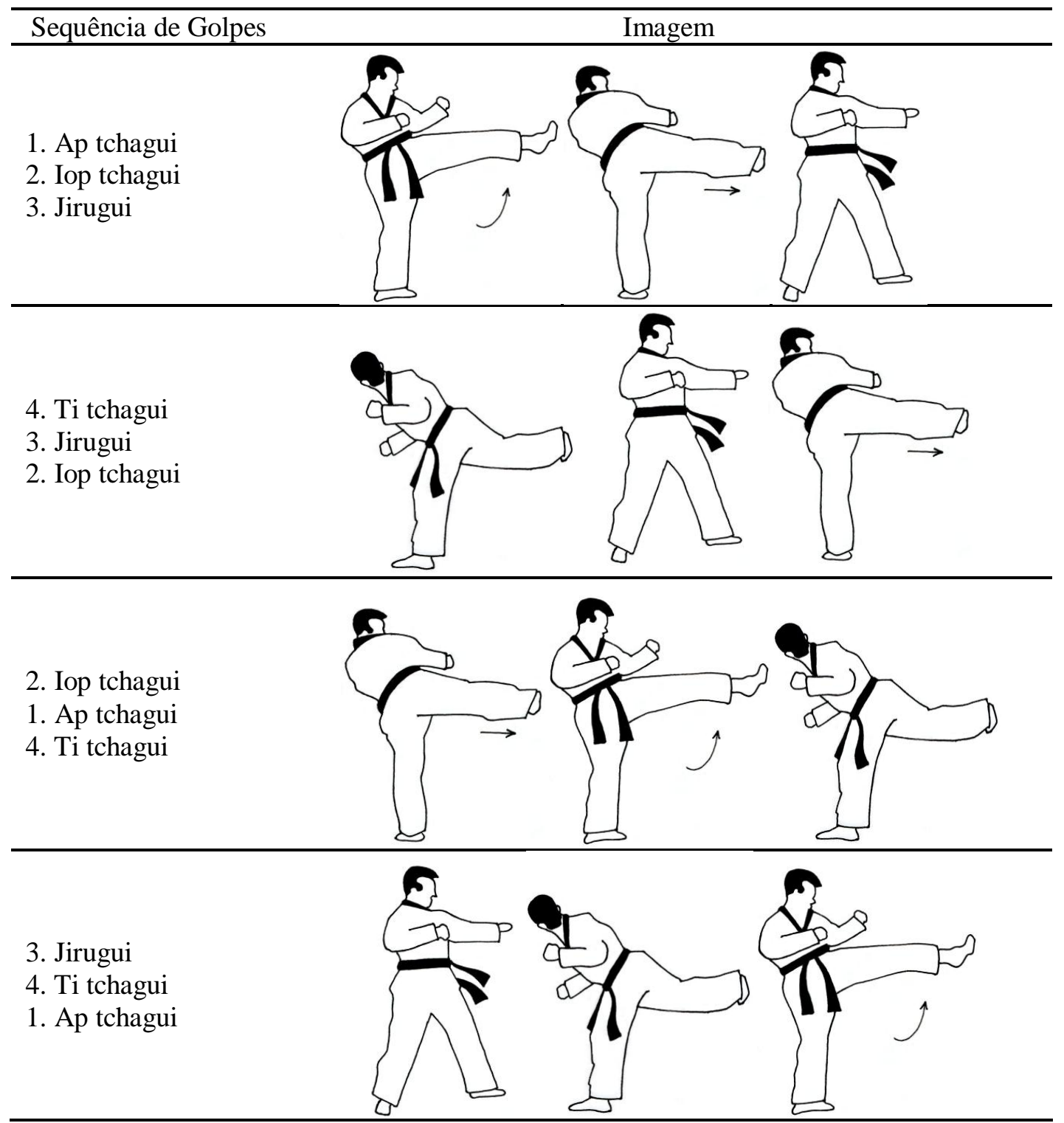

Treino de revisão. Após o final de cada condição, a sessão seguinte era iniciada com um Treino de Revisão que consistia em realizar um minuto de cada golpe/sequência de golpes ensinados, porém somente com foco móvel. O objetivo era realizar uma revisão antes do teste.

Testes de luta simulada. No início e final de cada condição experimental foi realizado um teste que simula uma situação de luta com adversário, com o objetivo de 
avaliar o efeito dos diferentes treinos sobre o desempenho em situação de luta. Foi programada uma situação de luta similar à de uma luta olímpica de Taekwondo.

Como na luta olímpica, tanto o participante quanto o instrutor (agora oponente) podiam desferir golpes. Porém, os ataques do oponente foram previamente programados entre aqueles definidos para ensino neste estudo (Tabelas 5 e 6). Os ataques foram planejados em ordem semirrandômica de modo que todos os golpes ensinados eram emitidos pelo menos duas vezes durante a luta. Após a execução de cada ataque, o oponente dava uma pausa de aproximadamente cinco segundos para dar tempo de o participante emitir alguma resposta.

Os ataques não foram executados com força pelo oponente, que, no máximo, encostava os punhos e pés no protetor do participante. A duração da simulação de luta foi de dois rounds de um minuto cada apena, com um intervalo de 30 segundos para descanso. A experimentadora/observadora sinalizava o início e a finalização de cada período de tempo. Nas lutas simuladas não havia indicação de pontos ou faltas.

A instrução dada pelo instrutor era: “Agora vamos fazer uma simulação de luta de Taekwondo. Eu vou fazer alguns movimentos, como chutes e socos, na sua direção. Não se preocupe, não vou te machucar, pois esses ataques vão ser com força e velocidade controladas. Você deve reagir aos ataques da forma como achar melhor, evitando atacar cabeça e partes íntimas. Durante esta fase estamos avaliando o que você já sabe fazer. Vamos lutar em dois rounds para não ficar muito cansativo".

Teste de luta final. Esse teste foi realizado no final do experimento e teve o mesmo tempo de duração que os anteriores; porém, agora o oponente realizava movimentações e ataques adicionais de Taekwondo que não foram contemplados nos treinos e em sequências maiores ou menores, para colocar o participante em uma 
situação mais próxima de uma luta real. Não foram realizados chutes na cabeça pois, por questão da segurança, somente são permitidos em lutas entre atletas faixa-preta.

A instrução dada foi “Agora você fará uma luta similar às lutas anteriores, com a diferença de que será mais similar a uma luta real de Taekwondo, pois poderei fazer alguns golpes e movimentações que você ainda não viu. Como nas outras vezes, não se preocupe com a força, somente irei encostar as áreas com meu pé ou meus punhos”.

\section{Acordo entre observadores}

Os treinos contaram sempre com pelo menos um observador presencial e outro que poderia ser presencial ou por vídeo. Os observadores foram treinados a registrar, nos treinos, a frequência de movimentações, golpes ou sequências emitidos pelos participantes. O participante piloto para treinamento do instrutor também serviu de treino para os observadores. O acordo por intervalo foi de $100 \%$, ou seja, sempre houve acordo com relação à quantidade de blocos de $30 \mathrm{~s}$ que foram registrados em cada sessão. O acordo das frequências dentro dos intervalos (quantidade de golpes a cada bloco de 30 s) para cada golpe e sequência variou entre 93 e $100 \%$.

A observação dos testes foi toda realizada por vídeo. Nas lutas simuladas foram registrados golpes, sequências, movimentações no tatame e comportamentos defensivos do instrutor/oponente e do participante com códigos determinados pela experimentadora. Cada interação participante-oponente era representada em uma linha da folha de registro. As frequências foram contadas a partir dos dados registrados. Em caso de desacordo, um terceiro observador era convidado. Para fins de análise foram considerados dois registros iguais.

\section{Resultados}

Com relação às respostas ao questionário pré-experimental, não foi observada relação entre a prática de atividade física (todos praticavam algum tipo) e conhecimento 
prévio de artes marciais (televisão, filme e videogame) e o desempenho dos participantes nas fases de treino e teste do experimento. Também não houve diferença de sexo e idade dos participantes.

A partir das observações e transcrições das filmagens, foram analisados os comportamentos emitidos pelos participantes durante as etapas de treino e teste, assim como o tempo para atingir os critérios de aprendizagem. Os comportamentos incluíram movimentações, defesas, golpes e sequências ensinados e novos. Todos os participantes alcançaram o critério de aprendizagem nas fases de ensino e realizaram os testes de luta simulada em até quatro horas distribuídas por, no máximo, cinco sessões.

As movimentações básicas foram aprendidas por todos os participantes em $1 \mathrm{ou}$ 1,5 min, como mostrado na Tabela 7. Seis participantes necessitaram de correções e extensão do tempo mínimo (1 min) para o ensino das movimentações, mas nenhum participante foi corrigido mais de uma vez por exercício. Os participantes P4 e P8 não necessitaram nenhum tipo de correção.

Tabela 7

Tempo de Treino dos Participantes para Cada Movimentação

\begin{tabular}{lcccccccc}
\hline \multirow{2}{*}{ Treino de movimentação } & \multicolumn{7}{c}{ Participante } \\
\cline { 2 - 9 } & P1 & P2 & P3 & P4 & P5 & P6 & P7 & P8 \\
\hline Troca de base no lugar & 1 & 1 & 1 & 1 & 1 & 1 & 1 & 1 \\
Troca de base pra frente & 1 & 1,5 & 1,5 & 1 & 1 & 1,5 & 1 & 1 \\
Troca de base pra trás & 1 & 1 & 1 & 1 & 1 & 1 & 1,5 & 1 \\
Exercício & 1,5 & 1 & 1,5 & 1 & 1,5 & 1 & 1 & 1 \\
\hline
\end{tabular}

Nos treinos de golpes e sequências não houve diferença sistemática relacionada à ordem de exposição às condições a partir de inspeção visual e análise estatística de diferença entre as médias das durações dos treinos dos grupos expostos às duas ordens (Teste t, p>0,05). Assim, essa variável será desconsiderada nas demais análises do treino. 
A Figura 4 mostra o tempo de treino (em minutos) para cada participante alcançar o critério de aprendizagem nas etapas de treino para todos os golpes unitários e sequências. O tempo de treinamento necessário para finalizar as etapas de treino diminuiu ao longo das mesmas: Aquisição $(M=8,16$; $D P=1,66)$, Foco Fixo $(M=7,09$; $\mathrm{DP}=1,14)$, Foco Móvel (M=6,81; $\mathrm{DP}=0,79)$ e Revisão $(\mathrm{M}=4,37 ; \mathrm{DP}=0,34)$.

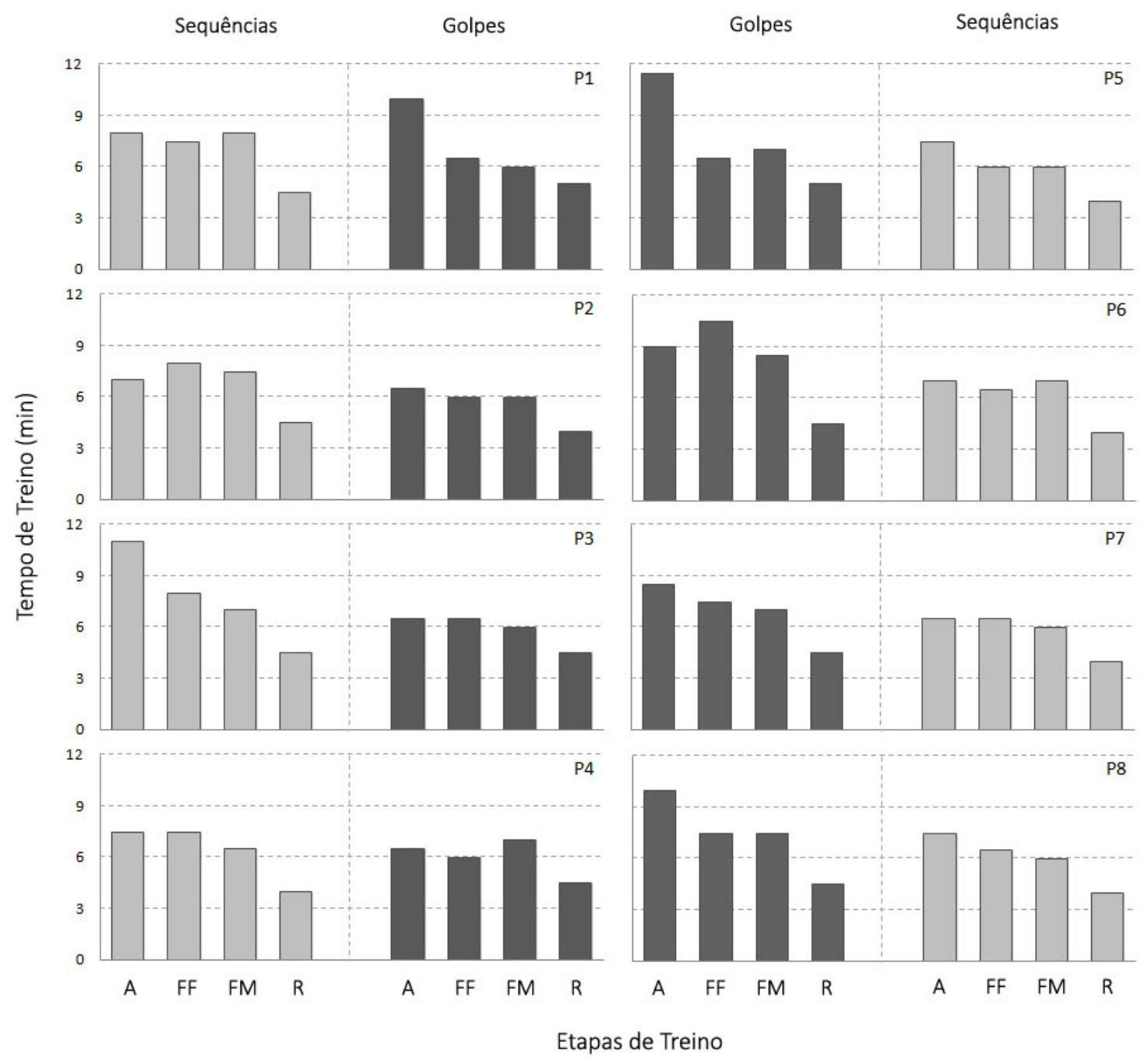

Figura 4. Tempo de treino (min) das etapas de treino do total de golpes unitários e sequências: Aquisição (A), Foco Fixo (FF), Foco Móvel (FM) e Revisão (R) para cada participante.

Os participantes se aproximaram cada vez mais do tempo mínimo exigido para completar uma etapa, que incluía o ensino de todos os golpes/sequências (4 min para a Revisão e 6 min para as demais fases). Na etapa de Revisão, realizada antes das lutas, 
observa-se que cinco dos participantes (P4 a P6) atingiram o critério no tempo mínimo e os outros três (P1 a P3) necessitaram de apenas uma correção.

Todos os participantes que iniciaram com o treino de Sequências (M=6,02; $\mathrm{DP}=1,29)$ necessitaram de menos tempo total para atingir o critério de aprendizagem no treino de Golpes $(\mathrm{M}=7,20 ; \mathrm{DP}=1,98)$. Na análise por etapas do treino, apenas $\mathrm{P} 1$ precisou de mais tempo de treino na etapa de Aquisição do treino de Golpes (11,5 min) do que havia sido necessário no treino de Sequências (7,5 min). P4 recebeu apenas uma correção a mais na etapa de Foco Móvel da Condição Sequências.

Os participantes que iniciaram pela Condição Golpes necessitaram de menos tempo para atingir o critério de aprendizagem no treino de Sequências tanto quando o tempo total de ensino de todas as etapas é considerado, quanto quando se considera o tempo em cada etapa de treino. Em resumo, o critério de aprendizagem foi atingido mais rapidamente na segunda condição a qual os participantes foram submetidos (seja de golpes ou sequências). Assim, não houve efeito de ordem de exposição às condições experimentais.

A Figura 5 mostra os resultados dos quatro testes que consistiram em lutas simuladas de Taekwondo: Pré-teste, Teste Pós-Golpes, Teste Pós- Sequências e PósTeste Final. Foram separados para análise os golpes e sequências ensinados e novos emitidos pelos participantes nesses testes. Foi considerado "novo" todo golpe ou sequência com topografia diferente daquela ensinada (definida no procedimento). Sequências novas incluíram sequências com número de golpes diferente do ensinado (três) e sequências que continham golpes não ensinados ou em ordem não ensinada. Foi desconsiderado nesta análise se os participantes acertaram os golpes no protetor do oponente ("fizeram pontos"). 


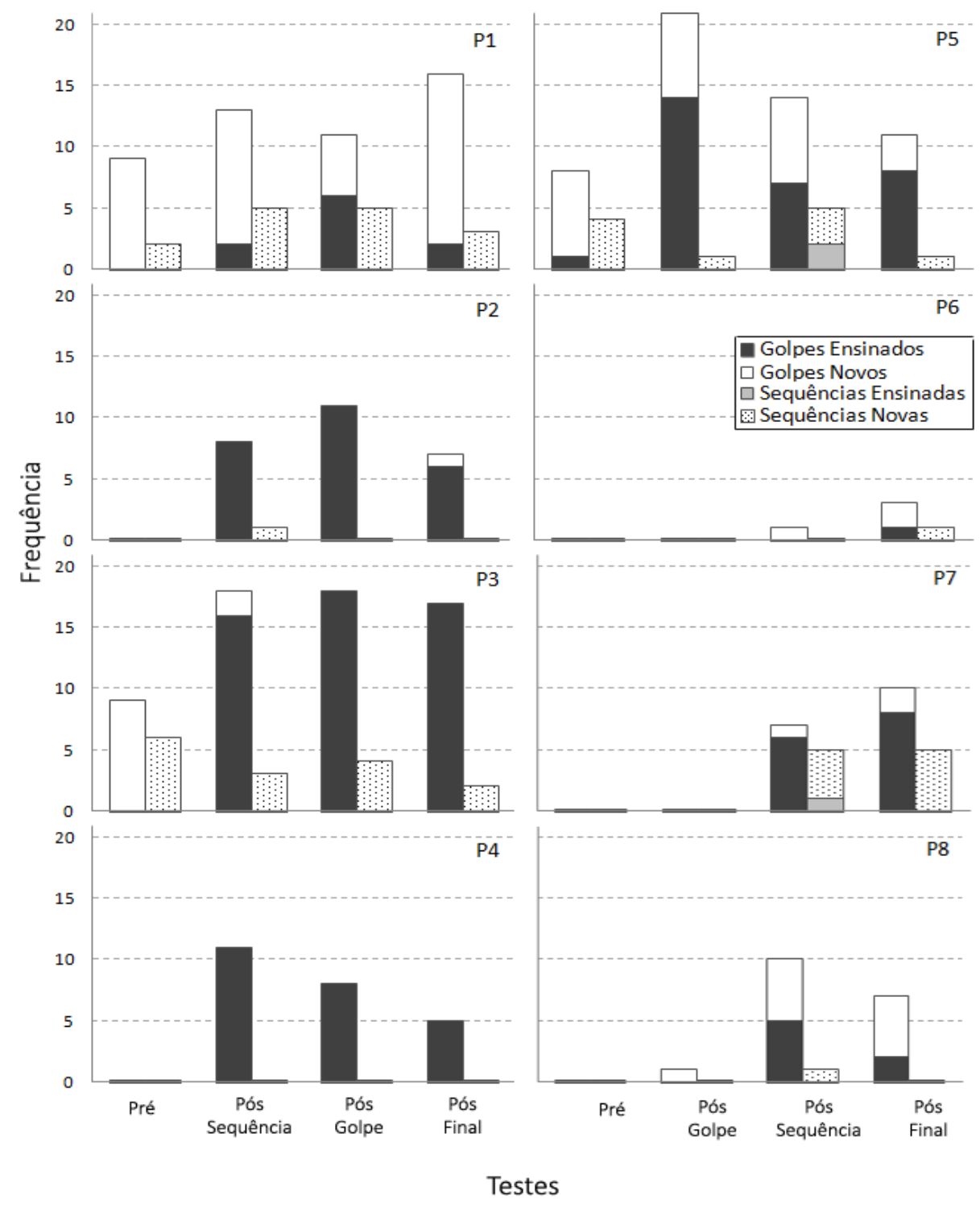

Figura 5. Frequência de golpes e sequências novos e ensinados emitidos pelos participantes nas fases de teste: Pré-Teste, Teste Pós-Sequência, Teste-Pós Golpes e Pós Teste Final.

No pré-teste, somente os participantes P1, P3 e P5 emitiram golpes e sequências. Golpes unitários novos foram emitidos com maior frequência (socos e chutes). P5 foi o único participante a imitar um golpe do instrutor (jirugui). Os demais golpes eram de três tipos: (1) similares aos emitidos pelo adversário (ex.: soco com o punho direito; soco esquerdo sem trocar de base); (2) similares a golpes permitidos no Taekwondo, mas que não foram ensinados no procedimento; e (3) similares a não permitidos no Taekwondo, mas permitidos em outras modalidades de luta (ex. chute na altura da 
canela). As sequências envolviam somente socos (ex. soco direito, soco esquerdo) ou socos e chutes, nenhuma incluiu somente chutes. Todos os participantes emitiram comportamentos defensivos (não incluídos na análise) quando eram atacados, que consistiam em movimentações de afastamento com relação ao oponente (para trás ou para o lado) e/ou movimentação dos braços protegendo o próprio corpo.

Após os treinos de golpes e sequências, todos os participantes aumentaram a frequência de ataques (golpes e sequências) com relação ao Pré-Teste. Os participantes P6 e P7, porém, aumentaram a frequência apenas no pós-teste da segunda condição (Pós-Sequências). A quantidade de ataques variou entre os participantes e entre os póstestes. O adversário atacava no máximo 16 vezes durante os dois minutos de luta simulada. Três participantes atacaram 16 ou mais vezes durante as lutas simuladas (P1 Pós Final, P3 - todos os pós-testes e P5 - Pós-Golpes). Os demais participantes atacaram menos de 12 vezes em todos os pós-testes. O participante P6, em especial, somente desferiu um ataque no teste Pós-Sequências e quatro no Teste Final.

Em geral, golpes unitários predominaram para todos os participantes em todos os pós-testes, independentemente do tipo de treino. A frequência de golpes ensinados aumentou no teste Pós-Golpes para os participantes que passaram primeiro pela condição Sequências (exceto P4). P6 dimiuiu a frequência de golpes após o ensino de sequências.

Os participantes P1, P3 e P5 emitiram sequências em todas as lutas (inclusive no pré-teste). P4 foi o único a não emitir sequências em nenhuma luta. Os demais participantes emitiram sequências em somente uma (P2, P6 e P6) ou duas (P7) lutas simuladas, sempre imediatamente após o treino de sequências.

Os golpes unitários ensinados ocorreram com maior frequência do que golpes novos nas lutas, exceto para P1 no teste Pós-Sequências e no Pós-teste Final. Dentre os 
golpes unitários ensinados, Iop tchagui foi o mais executado nas lutas simuladas (54 vezes no total). Jugui (42) e Ap tchagui (38) seguiram, em ordem de frequência. Ti tchagui foi o golpe menos executado pelos participantes, emitido apenas por metade dos participantes (P1, P2, P3 e P8)

Os golpes novos emitidos pelos aprendizes podem ser classificados em quatro tipos (Tabela 8): (1) soco com a mão direita, similar ao ensinado (Jirugui); (2) socos não ensinados; (3) chute com a perna direita similar ao ensinado (Ap tchagui); e (4) chutes não ensinados, permitidos no Taekwondo. Nenhum dos chutes ensinados com a perna direita (Iop tchagui e Ti tchagui) foram executados com a perna esquerda pelos participantes. P1 foi o participante a emitir mais golpes não ensinados. Os demais participantes emitiram predominantemente o soco com o membro direito.

Tabela 8

Tipos de Golpes "Novos” Emitidos pelos Participantes nos Pós-testes

\begin{tabular}{ccccc}
\hline \multirow{2}{*}{ Participante } & \multicolumn{2}{c}{ Soco } & \multicolumn{2}{c}{ Chute } \\
\cline { 2 - 5 } & Mão Direita & Novo & Pé Direito & Novo \\
\hline P1 & 2 & 11 & 0 & 16 \\
P2 & 0 & 0 & 1 & 0 \\
P3 & 3 & 0 & 0 & 0 \\
P4 & 0 & 0 & 0 & 0 \\
P5 & 6 & 1 & 3 & 2 \\
P6 & 4 & 1 & 0 & 0 \\
P7 & 2 & 2 & 0 & 0 \\
P8 & 7 & 1 & 1 & 2 \\
\hline
\end{tabular}

Nota. O soco com a mão direita e o chute com o pé direito foram golpes semelhantes aos ensinados com o membro esquerdo.

Quanto às sequências, houve predominância de novas. Apenas P5 e P7 emitiram sequências ensinadas no teste Pós-Sequências. As sequências novas que ocorreram nos pós-testes foram classificadas em três tipos (Tabela 9): (1) sequências novas com todos os golpes ensinados; (2) sequências com um golpe ensinado; (3) sequências sem golpes ensinados. P2, P3 e P7 emitiram predominantemente sequências que continham 
somente golpes ensinados. Essas sequências continham dois em vez de três golpes. Esse tipo de sequência ocorreu principalmente depois do treino de sequências.

Tabela 9

Tipos de Sequências “Novas” Emitidas pelos Participantes nos Pós-testes

\begin{tabular}{cccc}
\hline Participante & $\begin{array}{c}\text { Somente golpes } \\
\text { ensinados }\end{array}$ & 1 golpe ensinado & $\begin{array}{c}\text { Nenhum golpe } \\
\text { ensinado }\end{array}$ \\
\hline P1 & 0 & 2 & 10 \\
P2 & 1 & 0 & 0 \\
P3 & 9 & 1 & 0 \\
P4 & 0 & 0 & 0 \\
P5 & 2 & 4 & 2 \\
P6 & 0 & 0 & 1 \\
P7 & 10 & 1 & 0 \\
P8 & 0 & 1 & 0 \\
\hline
\end{tabular}

O pós-teste final foi o único teste em que o instrutor, agora na função de oponente, emitia golpes e sequências que não foram ensinados no experimento. Para cinco participantes houve diminuição do número de ataques com relação ao teste realizado imediatamente antes (isto é, Teste Pós-golpe para o grupo que iniciou com as sequências e Pós-sequência para o grupo que iniciou com os golpes). Para os três participantes que mostraram aumento do número de ataques, P1 aumentou a quantidade de golpes unitários novos. P2 emitiu um golpe novo pela primeira vez no estudo. P7 emitiu um golpe ensinado e uma sequência nova, algo que não havia ocorrido nas outras lutas.

Dos participantes que começaram com desempenho zero, os que passaram pela ordem sequência-golpe apresentaram em geral desempenhos mais altos nos testes do que os que foram expostos à ordem golpe-sequência, sendo que para esses últimos o desempenho nas lutas melhorou apenas na segunda condição. Assim, houve efeito de ordem de exposição considerando o efeito das condições sobre o desempenho nos testes. 
A porcentagem de acertos (acertos/golpes x 100) em cada luta simulada foi contabilizada para cada participante (Figura 6). Foram considerados acertos golpes desferidos pelos participantes que encostavam no protetor de tórax ou no braço rente ao corpo do oponente (instrutor). Golpes no ar ou em outras regiões do corpo do oponente (e.g., perna) foram considerados incorretos. Todos os golpes, inclusive aqueles contidos nas sequências, foram considerados individualmente nesta análise, assim como em uma competição de Taekwondo.

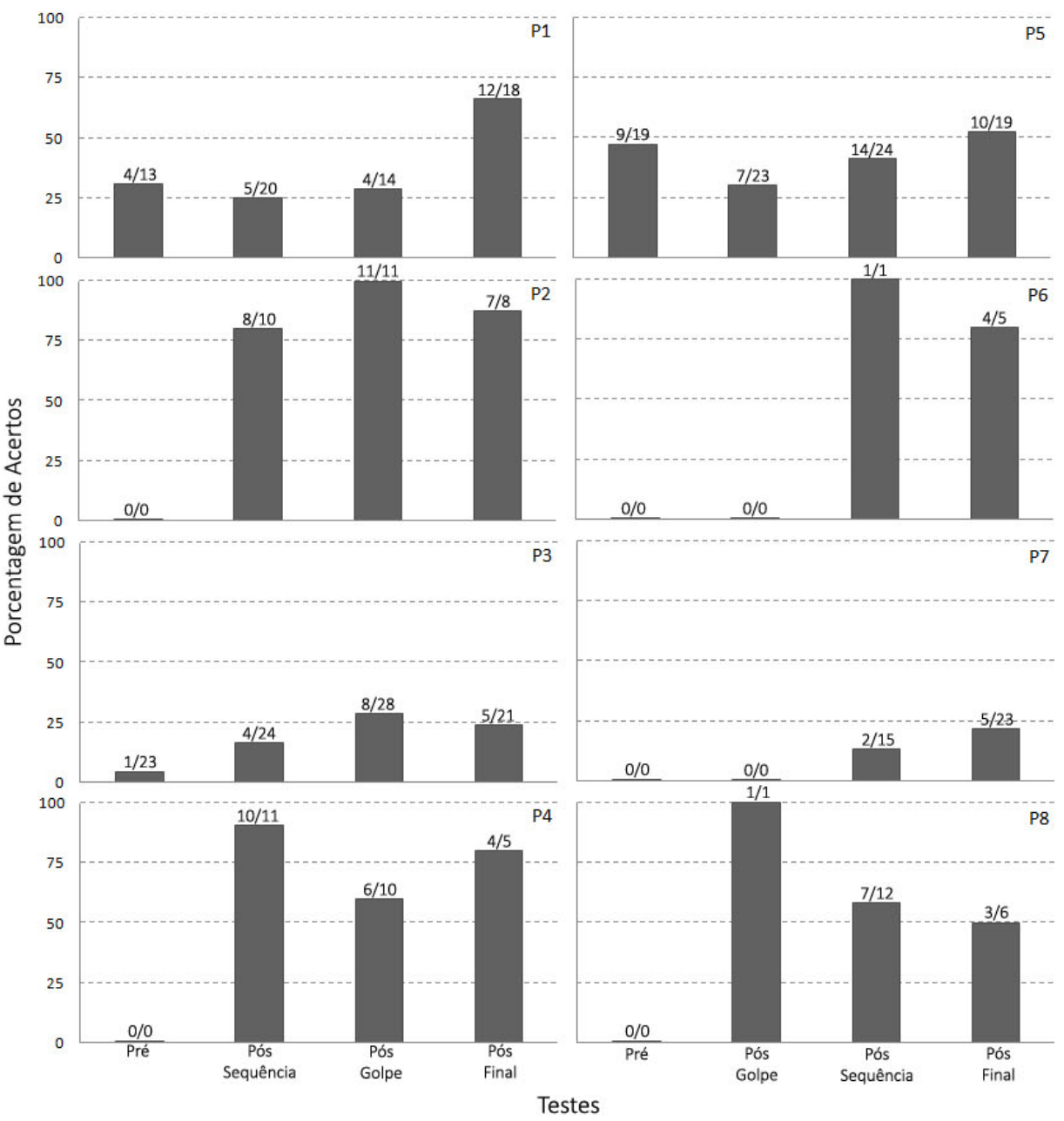

Figura 6. Porcentagem de golpes que tocaram o protetor ou o braço rente ao corpo do oponente nas fases de teste: Pré-Teste, Teste Pós-Sequência, Teste-Pós Golpes e Pós Teste Final. Os valores indicados acima das barras se referem à proporção de acertos por quantidade de golpes emitidos.

No Pré-teste, os três participantes que emitiram algum golpe acertaram o oponente em menos de 50\% das vezes. Para a maioria dos participantes (P1 a P3 e P5 a 
P7) houve aumento na porcentagem de acertos dos golpes da segunda para a terceira luta simulada. Ou seja, após a segunda condição, o desempenho dos participantes melhorou. P6 e P8 apresentaram desempenho de 100\% no teste Pós-Sequências e PósGolpes respectivamente, porém foi emitido apenas um golpe nessa luta. P2 acertou 11/11 golpes no teste Pós-Golpes.

A porcentagem de acertos independeu da ordem das condições. Metade dos participantes (P2, P4, P6 e P8) teve mais de 50\% de acertos nos testes Pós-Golpes e Pós-Sequências. Dois participantes (P1 e P5) apenas atingiram 50\% no Pós-teste Final. P3 e P7 não acertaram metade dos golpes em nenhum dos testes aos quais foram expostos.

\section{Discussão}

Estudos atuais na área da Análise Comportamenal Esportiva têm avaliado procedimentos de aprendizagem com objetivos de aquisição de habilidades, melhoria de desempenho e generalização para contextos competitivos. O presente estudo faz parte de uma nova linha de pesquisas que relaciona a Análise do Comportamento à Psicologia do Esporte, investigando metodologias para o ensino de repertórios básicos de artes marciais e avaliando se ocorre generalização com combinação e recombinação desses repertórios em contextos competitivos. O presente trabalho teve como objetivo geral estudar o efeito da aprendizagem de golpes unitários e sequências de golpes de Taekwondo, esporte pouco explorado na literatura, sobre o desempenho em lutas simuladas. Para tal, foi realizada uma replicação sistemática do estudo de França (2013).

Considerando a novidade do tema, foi importante, em primeiro lugar, identificar e definir golpes e sequências do Taekwondo para serem ensinados. Foram identificados quatro golpes de Taekwondo (um soco e três chutes) e quatro sequências compostas por 
três desses golpes. Os golpes foram escolhidos pelo nível de dificuldade, facilidade de registro e área de impacto no oponente, conforme descrito no procedimento. Cada golpe foi definido operacionalmente para este estudo. Os golpes que ocorreram nas lutas eram considerados como ensinados somente quando se adequavam a topografia descrita no procedimento.

As sequências de três golpes foram escolhidas de modo que cada golpe aparecia uma vez no início, uma no meio e uma no final de cada sequência. A sobreposição de elementos em diferentes estímulos é uma das variáveis que tem sido demonstrada como importante para a emergência de aprendizagem recombinativa (Goldstein, 1983; Hanna e cols., 2008). A quantidade de golpes que compunham uma sequência foi escolhida de modo a não ser muito pequena nem excessiva para um contexto de luta e para se assemelhar à extenção das sequências utilizadas por França (2013). A quantidade de sequências foi escolhida de modo a não esgotar as variações de sequências possíveis e para padronizar a quantidade de treino. Em França (2013), foram ensinados seis golpes e quatro sequências e o tempo mínimo variava entre etapas. No presente estudo, além de igualar o número de golpes e sequências, o tempo mínimo para cada uma das três etapas de treinos era 4,5 min (somando todos os golpes/as sequências). Isso garantiu que todos os participantes realizassem o mínimo de tempo de treino independentemente da condição experimental e facilitou a comparação entre as duas condições.

Um dos objetivos específicos envolveu avaliar se o uso de modelagem, modelação e instrução (Catania, 1999; Pierce \& Cheney, 2004) por um instrutor treinado era suficiente para que os participantes aprendessem as habilidades ensinadas. Assim como no estudo de França (2013), os procedimentos de ensino foram suficientes para que todos os participantes alcançassem o critério de aprendizagem nas etapas de ensino. 
As propriedades do treino planejado no presente experimento podem ter sido responsáveis pelo sucesso dos participantes nos treinos. A execução correta das movimentações e ataques (comportamento final desejado) foi previamente definida operacionalmente (Tabelas 4, 5 e 6). O ensino individualizado permitiu que o instrutor produzisse consequências imediatas para os comportamentos do participante e aumentasse gradativamente o nível de exigência. Apesar de as consequências serem subjetivas - ou seja, o que pode funcionar como reforço para uma pessoa não necessariamente ocorre para outra (Millenson, 1967) - o fato de os participantes terem atingido o critério de aprendizagem permite afirmar que as consequências foram reforçadoras para os mesmos. Essas características são consideradas imprescindíveis para que comportamentos novos se desenvolvam por modelagem (Catania, 1999; Pierce \& Cheney, 2004).

As instruções dadas tiveram o objetivo de direcionar a atenção dos participantes a aspectos complexos dos elementos do comportamento dos mesmos (e.g., dobrar mais o joelho) e do ambiente (e.g., consequências dos ataques, como o som produzido pelo toque no aparador). Com modelação, o instrutor forneceu um modelo preciso da topografia de um repertório complexo (movimentações e ataques de Taekwondo) e de interação do comportamento com o ambiente.

Nos treinos de movimentações básicas, os participantes atingiram o critério de aprendizagem quase sem correções. O objetivo principal do Treino de Movimentação era a manutenção da distância correta entre os oponentes, uma habilidade importante na luta de Taekwondo. Observou-se que com este treino específico e curto o aprendiz utilizou essas habilidades tanto nas etapas de treino de Foco Móvel quanto nas lutas simuladas. Foi possível observar nas lutas que todos os participantes se movimentaram pela área definida no procedimento de forma similar à ensinada. A maioria das vezes 
que o adversário (instrutor) atacava ou se movimentava em direção ao participante, este se movimentava de modo a se afastar. Da mesma forma, se o oponente se afastava, o participante se aproximava, mantendo a distância entre eles.

Nos treinos de ataques (golpes e sequências), todos os participantes receberam mais de uma correção em todas as etapas de ensino (Aquisição, Foco Fixo e Foco Móvel). No estudo de França (2013), apenas um participante (de quatro) precisou receber correções. Essa diferença ocorreu, provavelmente, por dois motivos. Em primeiro lugar, os critérios de aprendizagem foram diferentes. França exigia 100\% de acertos durante um minuto na etapa de Aquisição e durante os últimos 30s (de um tempo mínimo de 2 min) nas etapas de Foco Fixo e Foco Móvel. No presente estudo o tempo mínimo era de 1,5 min para todas as etapas e em cada bloco de $30 \mathrm{~s}$ eram observados erros, permitindo padronizar o tempo entre etapas de treino e entre condições. Dois erros consecutivos eram corrigidos com uma observação ou demonstração do instrutor e mais um bloco era acrescentado ao treino.

Além disso, a topografia dos golpes escolhidos para os estudos foi diferente. Em França (2013), os seis golpes ensinados envolviam três tipos de golpes que eram realizados tanto com o lado direito quanto com o esquerdo (e.g., soco esquerdo alto e soco direito alto). Neste estudo, todos os golpes eram diferentes, metade realizada com o lado esquerdo e a outra metade com o lado direito. O objetivo dessa mudança foi a possibilidade de se observar generalização na situação nova (luta simulada); ou seja, se golpes aprendidos com um lado seriam realizados com o outro, sem treino direto. Não obstante, pode-se afirmar que, assim como em França (2013) com Karate-do, todos os participantes aprenderam rapidamente todos os golpes (até $4 \mathrm{~h}$ ) se comparado com o ensino tradicional de Taekwondo, que envolve meses de aulas (Kim \& Silva, 2000). 
Como mencionado anteriormente, o ensino tradicional de artes marciais envolve a aprendizagem de uma multiplicidade de ataques e movimentações, além de contraataques, poomse, exercícios de defesa pessoal e, muitas vezes, a filosofia da arte marcial. Assim, apesar da rápida aprendizagem demonstrada pelos resultados, limitações de tempo e controle experimental não permitem ensinar tudo que o Taekwondo teria a oferecer. Seria interessante comparar mais diretamente o ensino de alguns ataques utilizando o método aqui sugerido com o ensino por métodos mais tradicionais; porém, apesar de existirem orientações gerais sobre o conteúdo a ser ensinado e características de um bom professor (Goulart \& Campos, 2011), não são encontrados na literatura métodos de ensino sistematizados.

Neste estudo buscou-se também comparar o treino de golpes unitários com o de sequências de golpes. Os resultados mostraram que não há diferença entre aprendizagem por golpes ou sequências em termos de tempo para atingir o critério de aprendizagem. Observou-se, apenas, efeito de história, ou seja, os participantes atingiam o critério mais rapidamente na segunda condição, independentemente do treino ser de golpes ou sequências.

Na etapa de Aquisição foi necessário um tempo maior para atingir o critério de aprendizagem do que nas etapas de Foco Fixo e Foco Móvel. Nessa etapa se realizava pela primeira vez o treino do golpe ou sequência; assim, a ocorrência de erro era mais provável do que nas duas etapas seguintes. Esse resultado é semelhante ao obtido por França (2013), mas o mesmo observou diferença entre as condições - o treino de sequências demorou mais. $\mathrm{O}$ fato de o tempo de treino ter sido igualado neste estudo para ambas as condições pode ter contribuído para a diferença nos resultados.

Os treinos com poucos erros e com aprendizagem em pouco tempo de "aula" sugerem que os procedimentos de modelagem, modelação e instrução foram eficazes 
para ensinar novos comportamentos. As diferenças entre o procedimento neste estudo e o utilizado em academias incluem o ensino individualizado que garantia a aprendizagem antes de passar para uma nova etapa; o planejamento de um número pequeno de objetivos de ensino por sessão; ofeedback imediato para acertos, erros e progressos; e a ausência coerção pelo instrutor, entre outros. Esses fatores podem ter reduzido o tempo e aumentado a velocidade da aprendizagem, pois são aspectos do controle do comportamento operante importantes para garantir aprendizagem (Catania, 1999; Pierce \& Cheney, 2004).

No presente estudo, avaliou-se o efeito do ensino das habilidades de Taekwondo sobre o desempenho em situação de luta simulada. Os resultados mostraram que, independentemente da ordem de ensino, o treino tanto de golpes quanto de sequências produziu aumentos nas frequências de ataques dos participantes. Porém, como descrito anteriormente, o contexto de treino difere bastante daquele de luta e a generalização não ocorre imediatamente (Cillo, 2003).

Alguns participantes, apesar de terem aprendido golpes e sequências, atacaram pouco ou nada ao longo das lutas simuladas. Como isso ocorreu somente com participantes que passaram pela Condição Golpes primeiro, é possível que um treino de golpes não induza ataques na situação de luta, da mesma maneira que um treino de sequências. Porém, como ainda são poucas pesquisas na área, outras hipóteses podem ser levantadas como falta de clareza nas instruções, a mudança para um contexto competitivo e a pouca experiência dos participantes com a arte marcial. Sugere-se que em experimentos futuros as instruções sejam bastante explícitas na necessidade de o participante se engajar ativamente na luta.

Esses resultados possívelmente tem relação com as diferenças das contingências de treino e testes. O planejamento de um treinamento precisa incluir aspectos já 
apontados na literatura como importantes para aumentar a probabilidade de generalização, como variar a situação de treino (Stokes, 1992; Stokes \& Baer, 1977). As três etapas de ensino do experimento tiveram o objetivo de aproximar gradativamente o contexto de treino ao de luta. Porém, nos treinos os participantes apenas realizaram os golpes e não tiveram experiência com ataques em direção a eles. Além disso, nenhuma etapa foi programada para reagir a ataques utilizando o que foi ensinado antes dos testes. Assim, é possível que sejam necessárias etapas adicionais para aproximar mais os dois contextos.

Estudos futuros podem avaliar a possibilidade de inclusão e uma quarta etapa nos treinos em que os participantes precisassem chutar e socar diretamente no protetor de tórax do instrutor, pois no presente estudo os treinos requeriam que o participante tocasse apenas no aparador. Outra alternativa seria trocar o aparador pelo protetor de tórax nas etapas de Foco Fixo e Foco Móvel. Esse tipo de estratégia pode se mostrar importante para que o aluno gradualmente desenvolva mais prontamente o repertório necessário para a luta. Além disso, seria interessante a inclusão de uma etapa de treino de ataques antecedidos por algum golpe do instrutor ou até acrescentar um número maior de alternações entre treinos e testes.

Na prática esportiva de modo geral, a forma correta de se executar um movimento pode ser um aspecto importante, mas não garante a produção dos efeitos desejados no ambiente (Catania, 1996). Assim, foi feita uma análise dos acertos nas lutas que seriam considerados pontos em uma luta real de Taekwondo. De maneira similar às lutas oficiais, pelo menos dois de três observadores precisaram considerar acerto para que fosse marcado como tal. Porém, nas lutas oficiais são considerados pesos diferentes para tipos de golpes diferentes e na presente análise todos os golpes tiveram peso 1 . Observou-se que, para seis participantes, houve um aumento na 
porcentagem de golpes que acertaram o protetor do oponente da luta após o primeiro treino para a luta após o segundo treino (Figura 6). Quando comparada com a análise dos golpes e sequências (Figura 5), é possível identificar a eficiência dos participantes na luta. Enquanto alguns (P1, P3 e P5) atacavam muito, mas acertavam pouco; outros (P6 e P8) atacavam pouco, mas acertavam muito.

Nas análises dos testes de luta simulada buscou-se também comparar o efeito do ensino de golpes unitários e sequências de golpes sobre a ocorrência de repertório combinado e recombinado (novo) de ataques de Taekwondo. Os testes de luta simulada incluíram somente golpes do instrutor que faziam parte do treino, para evitar imitação de comportamentos novos por parte dos participantes. Somente o Pós-teste Final de luta incluiu novos golpes, buscando maior semelhaça com uma situação de luta real. Mesmo com esse controle experimental os participantes emitiram alta frequência de golpes e sequências novos, indicando que os ataques emitidos pelos participantes nas lutas foram devidos à história de treinos e a situação nova de luta e não à imitação do oponente.

Dois dos participantes que passaram pela Condição Golpes primeiro não emitiram qualquer tipo de ataque na luta simulada desta condição. P5 foi o único a emitir uma sequência nova, mostrando a emergência de combinação de golpes. É necessário investigar se outras variáveis no treino de golpes unitários poderiam produzir aumento de ataques na luta, especialmente que envolvam combinação dos repertórios ensinados.

Três participantes que passaram pela Condição Sequências primeiro emitiram sequências novas; porém, além de serem sequências de apenas dois golpes, houve frequência consideravelmente maior de golpes unitários. Ocorreu um comportamento contrário da (re)combinação, ou seja, a segregação dos elementos que compõem uma unidade maior. É provável que características específicas de situações de luta (e.g., 
interrupções, contra-ataques e afastamento do oponente) tenham aumentado a probabilidade de ataques menos elaborados e com menor gasto de energia. É possível, também, que diferentemente da leitura, em que palavras compõe uma unidade funcional (significado) diferente de somente a soma de suas partes (letras, sílabas), nas artes marciais uma sequência seja justamente apenas a exata soma de suas partes (golpes).

Apesar de comportamentos como contra-ataques e afastamento do adversário serem muito comuns em lutas reais de Taekwondo, é sugerido, para fins de controle experimental, que em futuros experimentos o instrutor seja ensinado a ficar mais sensível às contingências presentes nos testes e menos sob controle exato do protocolo estabelecido para o experimento (regras sobre os golpes que deveria executar e do tempo entre golpes). É provavel que França (2013), que era tanto instrutor quanto experimentador no experimento, tenha ficado sobre controle de variáveis que um professor não analista do comportamento não ficaria. Em outras ocasiões pode o participante ter optado por não emitir o golpe considerado mais difícil (ti tchagui).

A grande maioria dos golpes considerados novos foram golpes idênticos aos ensinados exceto pelo uso do membro direito, quando no treino havia sido ensinado com o membro esquerdo. Nenhum dos chutes com a perna esquerda foi executado com a perna direita, provavelmente porque os participantes eram destros.

Os demais golpes foram todos executados na altura correta porém a execução não permitia encaixar na descrição dos golpes ensinados (e.g., o chute acertava a lateral do protetor com o peito do pé e não a sola). Os participantes atingiram o critério de aprendizagem de $100 \%$ de acerto no último bloco, estabelecido durante os treinos; no entanto, parece que o contexto de luta (e.g., possibilidade de interrupções e contraataques) levou alguns participantes a execução pobre de alguns golpes, não permitindo que fossem categorizados como ensinados. Esse fator parece ter aumentado a frequência 
de golpes unitários novos assim como de sequências novas, pois algumas continham esses elementos não ensinados.

Poucas sequências exatamente como ensinadas ocorreram nas lutas de modo geral. Apenas P5 e P7 fizeram sequências ensinadas, após o treino de sequências. Porém, a análise das sequências novas mostrou que, exceto por P1, a maioria das sequências "novas" emitidas continham dois elementos ensinados.

Estudos de aprendizagem recombinativa têm mostrado que o ensino de unidades de diferentes tamanhos (letras, sílabas e palavras) contribuem para o aprendizado da leitura de palavras novas recombinadas (de Souza e cols., 2014). Em uma luta de Taekwondo, é necessário emitir golpes e sequências de golpes variados para aumentar a probabilidade de obter pontos. De modo geral, o presente experimento mostrou que, independentemente da ordem de ensino, o treino tanto de golpes quanto de sequências produziu aumentos nas frequências de ataques novos dos participantes, que incluíam unidades previamente ensinadas.

O presente estudo constitiu em um avanço para a Análise Comportamental do Esporte ao produzir resultados elucidando algumas das variáveis envolvidas na prática do Taekwondo esportivo. O estudo contribuiu para o desenvolvimento de um procedimento de ensino de habilidades físicas e funcionais que já havia sido demonstrado em pesquisa anterior com Karate-do (França, 2013) e agora foi estendido para o Taekwondo, uma arte marcial com suas próprias características. Em segundo lugar, evidenciou algumas diferenças entre o comportamento cooperativo do treino e o competitivo de uma luta, como a baixa frequência do responder nas lutas (por alguns participantes) e a ocorrência de comportamentos novos, que não ocorriam nos treinos. Finalmente, trouxe informações relevantes sobre a generalização recombinativa aplicada em contexto de arte marcial. Estudos adicionais são necessários para identificar 
as condições de ensino que favorecem a generalização para lutas, bem como a recombinação de repertórios.

Outros aspectos que são complexos e necessários em um estudo como este podem trazer avanços para a área da Psicologia do Esporte. Futuros estudos precisam avançar nas análises funcionais para melhor definir tanto as características dos treinos quanto de lutas simuladas e reais. O presente estudo se limitou a um conjunto pequeno de habilidades básicas que podem ser ampliadas em outras pesquisas. Outra questão é a necessidade de aperfeiçoar o treinamento para professores de artes marciais. Apesar de já conhecerem bem a prática - nas artes marciais, quando um aluno se torna faixa preta está automaticamente habilitado a ser professor - podem se beneficiar de resultados de estudos como este, que ressaltam aspectos da melhoria da eficácia do ensino. Programas como o Train-to-Code (Treinamento-para-Codificar, tradução livre; Ray \& Ray, 2008) podem auxiliar no treinamento de professores e observadores para aumentar a exatidão e padronizar observações e correções dos comportamentos dos participantes que não se encaixam no critério estabelecido. É possível, ainda, o uso de câmeras com sensores de movimento (e.g., Microsoft Kinect) e softwares (e.g., NuiCapture ${ }^{\circledR}$ ) com os quais possam ser avaliados de forma automática e padronizada os comportamentos como se encaixando ou não nos critérios de aprendizagem. 


\section{Referências}

Barbosa, J. I. C. (2003). A criatividade sob o enfoque da análise do comportamento. Revista Brasileira de Terapia Comportamental e Cognitiva, 5(2), 185-193.

Batitucci, J. (2007). Paradigma de equivalência de estímulos no ensino de seqüências de notas musicais. Dissertação de mestrado não publicada, Universidade de Brasília, Brasília.

Brown, J. S. (1965). Generalization and discrimination. Em D. I. Mostofosky (org.), Stimulus Generalization. Stanford: Stanford University Press, pp. 7-23.

Catania, C. A. (1996). On the origins of behavior structure. Em T.R. Zentall e P.M. Smeets (org.), Stimulus class formation in humans and animals. New York: Elsevier. pp. 3-12.

Catania, C. A. (1999). Aprendizagem: comportamento, linguagem e cognição. (D. D. G. de Souza, Trad.) Porto Alegre: Artes Médicas.

Catania, C. A. (2001). Three types of selection and and three centuries. International Journal of Psychology and Psychological Therapy, 1(1), 1-9.

Cillo, E. N. P. (2003). Futebol brasileiro: um ensaio sob a ótica da análise do comportamento. Em H. M. Sadi, \& N. M. S. Castro (Orgs.). Ciência do Comportamento: conhecer e avançar, 3, 137-146. Santo André: Esetec.

Confederação Brasileira de Taekwondo (2014). Estatuto da Confederação Brasileira de Taekwondo CBTKD. Retirado de: http://cbtkd.org.br/noticia/8104902b311a927cec2af4da9. Acesso em $10 / 08 / 2014$

Delage, P. E. G. A., \& Carvalho Neto, M. B. (2010). Um modo alternativo de construir um operante: A aprendizagem recombinativa. Psicologia em pesquisa (UFJF), $4,50-56$. 
Delage, P. E. G. A. (2011). Transferência de aprendizagem no uso de ferramentas por macacos prego. Tese de doutorado, Universidade Federal do Pará, UFPA, Belém, PA, Brasil.

De-Farias, A. K. C. R. (2005). Comportamento Social: Cooperação, Competição e Trabalho Individual. Em Abreu-Rodrigues, J., \& Ribeiro, M. R. (orgs.). Análise do comportamento: Pesquisa, teoria e aplicação. Grupo A, 265-282.

de Rose, J. C, de Souza, D. G., \& Hanna, E. S. (1996). Teaching reading and spelling: Exclusion and stimulus equivalence. Journal of Applied Behavior Analysis, 29, 451-469.

de Souza, D. G., Hanna, E. S., Albuquerque, A. R., \& Hübner, M. M. C. (2014). Processos recombinativos: Algumas variáveis críticas para o desenvolvimento da leitura. Em de Rose, J. C., Gil, M. S. C. A., \& de Souza, D. G. (orgs.). Comportamento simbólico: Bases conceituais e empíricas. Marília: Oficina Universitária, 421-462.

Epstein, R. (1985). The spontaneous interconnection of three repertoires. The Psychological Record, 35, 131-141.

Epstein, R. (1987). The Spontaneous Interconnection of Four Repertories of Behavior in a Pigeon. Journal of Comparative Psychology, 101(2), 197-201.

Epstein, R., Kirshnit, C. E., Lanza, R. P., \& Rubin, L. C. (1984). 'Insight' in the pigeon: antecedents and determinants of an intelligent performance. Nature, 308, 61-62. França, T. P. (2008). Análise Comportamental Aplicada ao Karate-do. Monografia, Centro Universitário de Brasília, UniCEUB, Brasília, DF, Brasil. França, T. P. (2013). Ensino de golpes e sequências de ataque sobre o desempenho em luta simulada de Karate-do. Dissertação de mestrado não publicada, Universidade de Brasília, Brasília. 
Gillis, A. (2008). A Killing Art: The Untold History of Tae Kwon Do. Toronto: ECW Press.

Goldstein, H. (1983). Recombinative generalization - relationships between environmental-conditions and the linguistic repertoires of language learners. Analysis and Intervention in Developmental Disabilities, 3(4), 279-293.

Goldstein, H. (1993). Structuring environmental input to facilitate generalized language learning by children with mental retardation. In A. P. Kaiser \& D. B. Gray (Eds.). Enhancing children's communication: Research foundations for intervention (pp. 317-334). Baltimore: Paul H. Brookes.

Goulart, F., \& Campos, T. (2011). Taekwondo: O Caminho dos Pés e das Mãos. São Paulo: Online.

Hanna, E. S., Karino, C. A., Araujo, V. T., \& de Souza, D. G. (2010). Leitura recombinativa de pseudopalavras impressas em pseudo-alfabeto: similaridade entre palavras e extensao da unidade ensinada. Psicologia USP, 21, 275-311.

Hanna, E. S., Kohlsdorf, M., Quinteiro, R. S., Fava, V. M., de Souza, D. D. G., \& de Rose, J. C. (2008). Diferenças individuais na aquisição de leitura com um sistema lingüístico em miniatura. Psicologia: Teoria e Pesquisa, 24(1), 45-58.

Huber, E. R. (2010). Avaliação do ensino cumulativo de relações entre estímulos musicais sobre a formação de classes, o desempenho recombinativo e o tocar teclado. Dissertação de mestrado não publicada, Universidade de Brasília, Brasília.

Kim, J. Y., \& Silva, E. (2000). Taekwondo - Arte Marcial Coreana, Volume 2 Avançado. São Paulo: Roadie Crew.

Köhler, W. (1925). The mentality of apes. Mitchan: Penguin Books.

Lee, S. M., \& Ricke, G. (2005). Official Taekwondo Training Manual. New York: 
Sterling Publishing Co.

Lopes, H. C. (2009). Taekwondo - A arte coreana: do domínio à glória. Bauru, SP: Canal6.

McKenzie, T. L., \& Rushall, B. S. (1974). Effects of self-recording on attendance and performance in a competitive swimming training environment. Journal of Applied Behavior Analysis, 7(2), 199-206. doi:10.1901/jaba.1974.7-199

Martin, G. L., \& Thomson, K. (2011). Overview of Behavioral Sport Psychology. In J. K. Luiselli \& D. D. Reed (Eds.), Behavioral sport psychology: Evidence-based approaches to performance enhancement (pp. 3-21). New York: Springer.

Martin, G. L., \& Tkachuk, G. A. (2000). Behavioral sport psychology. In J. Austin \& J. E. Carr (Eds.). In Behavioral sport psychology: Handbook of applied behavior analysis, 399-422. Reno, NV: Context Press.

Mellalieu, S. D., Hanton, S., \& O'Brien, M. (2006). The effects of goal setting on rugby performance. Journal of Applied Behavior Analysis, 39, 257-261.

Millenson, J. R. (1967). Princípios de Análise do Comportamento. (A. A. Souza \& D. de Rezende, Trads.). Brasília: Coordenada.

Neves Filho, H. B. (2010). Efeito de diferentes histórias de treino sobre a ocorrência de “insight” em macacos-prego (Cebus spp.). Dissertação de mestrado, Universidade Federal do Pará, UFPA, Belém, PA, Brasil.

Pierce, W., \& Cheney, C. (2004). Behavior analysis and learning ( $3^{\text {rd }}$ ed.). Mahwah, NJ: Lawrence Erlbaum Associates.

Pimenta, T. F. F., \& Marta, F. E. F. (2002). Taekwondo: Sua Trajetória Rumo às Olimpíadas. Em: Congresso Brasileiro de História da Educação Física, Esporte, Lazer e Dança VIII. Ponta Grossa, PR: Universidade Estadual de Ponta Grossa.

Quinteiro, R. S. (2003). Aprendizagem de leitura receptiva e de comportamento textual: 
Efeito do número de palavras treinadas sobre o repertório recombinativo (Dissertação de Mestrado não publicada) Universidade de Brasília, Brasília, DF. Ray, J. M., \& Ray, R. D. (2008). Train-to-Code: An adaptive expert system for training systematic observation and coding skills. Behavior research methods, 40(3), 673-693.

Reed, D. D., Critchfield, T. S. \& Martens, B. K. (2006). The generalized matching law in elite sport competition: football play calling as operant choice. Journal of Applied Behavior Analysis, 39, 281-297.

Rios, G. B. (2005). O Processo de Esportivização do Taekwondo. Pensar a Prática, (8) $1,37-54$.

Roane, H. S. (2011). Behavioral momentum. In J. K. Luiselli \& D. D. Reed (Eds.), Behavioral sport psychology: Evidence-based approaches to performance enhancement (pp. 143-155). New York: Springer.

Roane, H. S., Kelley, M. E., Trosclair, N. M., \& Hauer, L. S. (2004). Behavioral momentum in sports: A partial replication with women's basketball. Journal of Applied Behavior Analysis, 37, 385-390.

Rodrigues-Neto, M. (2008). The Differential Effects of Public Posting and Goal-setting on Tactical Performances of Youth Basketball Players (Doctoral dissertation, The Ohio State University).

Romanowich, P., Bourret, J. \& Vollmer, T. R. (2007). Further analysis of the matching law to describe two- and three-point shot allocation by professional basketball players. Journal of Applied Behavior Analysis, 40, 311-315.

Rushall, B. S. (1970). An aspect of sprint training. Compete, 2(7).

Rushall, B. S., \& Pettinger, J. (1969). An evaluation of the effect of various reinforcers used as motivators in swimming. Research Quarterly. American Association for 
Health, Physical Education and Recreation, 40(3), 540-545.

Serejo, P., Hanna, E. S., de Souza, D. G., \& de Rose, J. C. C. (2007). Leitura e repertório recombinativo: efeito da quantidade de treino e da composição dos estímulos. Revista Brasileira de Análise do Comportamento, 2, 191-216.

Schultz, D. P., \& Schultz, S. E. (2009). A história da Psicologia moderna (S. S. M. Cuccio, Trad.). São Paulo: Cengage Learning.

Skinner, B. F. (1953/1981). Ciência e Comportamento Humano (J. C. Todorov e R. Azzi, trads.). São Paulo: Livraria Martins Fontes.

Skinner, B. F. (1974/1982). Sobre o Behaviorismo. (M. P. Villalobos, trad.). São Paulo, SP: Cultrix.

Skinner, B. F. (1981). Selection by consequences. Science, 213(4507), 501-504.

Stokes, T. F. (1992). Discrimination and generalization. Journal of applied behavior analysis, 25(2), 429-432.

Stokes, T. F., \& Baer, D. M. (1977). An implicit technology of generalization. Journal of applied behavior analysis, 10(2), 349-367.

Stokes, J. V., Luiselli, J. K., \& Reed, D. D. (2010). A behavioral intervention for teaching tackling skills to high school football athletes. Journal of Applied Behavior Analysis, 43, 509-512.

World Taekwondo Federation (2012). World Taekwondo Federation Competition Rules $\&$ Interpretation.

World Taekwondo Federation (2014). World Taekwondo Federation Statutes. 


\section{Anexo A}

\section{Questionário para participação de pesquisa}

1. a) Você já praticou alguma arte marcial ou esporte de luta que envolve socos e chutes (e.g. Karate, Taekwondo, Kung Fu - Wushu ou Sanshou, Krav Magá, Ninjutsu, Wing Tsun, Boxe, Kickboxe, Capoeira)?
$\square \operatorname{sim}$
Não

b) Se SIM, qual sua experiência com artes marciais/lutas?

2. Você tem costume de assistir, ao vivo e/ou pela televisão, a eventos de lutas como: Boxe Internacional, UFC (Ultimate Fighting Championship), Strikeforce, Pride, Bellator, DREAM ou campeonatos de artes marciais?
$\square \operatorname{sim}$
Não

Se sim, quais? Com que frequência?:

3. Você tem costume de assistir a filmes e/ou séries de televisão que envolvem cenas de lutas?
$\operatorname{sim}$
Não

Se sim, quais? Com que frequência?:

4. Você joga, em videogames, jogos de lutas como: Street Fighter, Mortal Kombat, Tekken e Soul Calibur?
$\operatorname{sim}$
Não

Se sim, quais? Com que frequência?:

5. Com que frequência você pratica atividades físicas?

6. Qual tipo de atividade(s) física(s) você pratica?
Dança
Futebol
Outros:

Brasília, de de 2014

Assinatura do/a participante 


\section{Anexo B \\ Termo de Consentimento Livre e Esclarecido}

Você está sendo convidado/a a participar da pesquisa "Ensino de golpes e sequências de ataque sobre o desempenho em luta simulada de Taekwondo", coordenado pela aluna de mestrado em Ciências do Comportamento Renata Cambraia, sob orientação da profa. Dra. Elenice Seixas Hanna (Universidade de Brasília - Instituto de Psicologia). Esta pesquisa envolve o ensino de algumas técnicas de Taekwondo e parte das atividades envolverão o ensino de técnicas simples como socos e chutes, e outra parte avaliará a utilização dessas técnicas em situações similares às de lutas. Assim, gostaria de consultá-lo(a) sobre seu interesse e disponibilidade de cooperar com a pesquisa.

A sua participação será através de aulas de Taekwondo e algumas simulações de luta onde não haverá contato físico real por parte do experimentador/instrutor. Essas aulas serão realizadas nas academias TKD Brasília (712/912 sul), Academia Gracie Barra (712 norte) ou Centro Olímpico da Universidade de Brasília, em até três encontros semanais. Cada encontro/aula terá duração entre 15 minutos e 60 minutos. É imprescindível comparecer à aula com roupas confortáveis, propícias para a realização de exercício físico.

Você receberá todos os esclarecimentos necessários antes, durante e após a finalização da pesquisa. Assinando este termo, você concorda em participar do estudo ciente de que os resultados poderão ser divulgados sem quaisquer informações que permitam identificá-lo/a, sendo mantido o mais rigoroso sigilo das informações sobre seu desempenho pessoal. Os dados provenientes de sua participação na pesquisa, tais como questionários, entrevistas, fitas de gravação ou filmagem, ficarão sob a guarda do pesquisador responsável pela pesquisa.

Sua participação é voluntária e livre de qualquer remuneração ou benefício. Você é livre para recusar-se a participar, retirar seu consentimento ou interromper sua participação a qualquer momento. A recusa em participar não irá acarretar qualquer penalidade ou perda de benefícios. Sua participação na pesquisa não implica em nenhum risco.

Este projeto foi revisado e aprovado pelo Comitê de Ética em Pesquisa do Instituto de Ciências Humanas da Universidade de Brasília - CEP/IH. As informações com relação à assinatura do TCLE ou os direitos do sujeito da pesquisa podem ser obtidos através do e-mail do CEP/IH cep ih@unb.br.

Este documento foi elaborado em duas vias, uma ficará com o/a pesquisador(a) responsável pela pesquisa e a outra com o senhor(a). Em caso de dúvidas em relação à pesquisa, por favor entre em contato com a pesquisadora Renata Cambraia, pelo telefone (61) 9138-0121, entre 09:00 e 20:00; ou para a profa. Elenice Seixas Hanna, telefone: (61) 9970-2312, entre 10:00 e 17:00.

Renata P. B. N. Cambraia
Elenice Seixas Hanna

Assinatura do/a participante

Brasília, de de 2014 


\section{Anexo C}

\section{Termo de Autorização para Utilização de Imagem e Som de Voz para fins de pesquisa}

$\mathrm{Eu}$, autorizo a utilização da minha imagem e som de voz, na qualidade de participante no projeto de pesquisa intitulado "Ensino de golpes e sequências de ataque sobre o desempenho em luta simulada de Taekwondo", sob responsabilidade de Renata Cambraia, vinculada ao Programa de PósGraduação em Ciências do Comportamento da Universidade de Brasília.

Minha imagem e som de voz podem ser utilizadas apenas para análise de dados e apresentação do estudo em congressos e palestras.

Tenho ciência de que não haverá divulgação da minha imagem nem som de voz por qualquer meio de comunicação, sejam elas televisão, rádio ou internet, exceto nas atividades vinculadas ao ensino e a pesquisa explicitadas acima. Tenho ciência também de que a guarda e demais procedimentos de segurança com relação às imagens e sons de voz são de responsabilidade da pesquisadora responsável.

Deste modo, declaro que autorizo, livre e espontaneamente, o uso para fins de pesquisa, nos termos acima descritos, da minha imagem e som de voz, contanto que seja garantido o anonimato.

Este documento foi elaborado em duas vias, uma ficará com a pesquisadora responsável pela pesquisa e a outra com o/a participante. de de 


\section{Anexo D \\ Questionário De Prontidão Para Atividade Física \\ (PAR-Q - Physical Activity Readiness Questionnaire)}

Este questionário tem objetivo de identificar a necessidade de avaliação clínica e médica antes do início da atividade física. Caso você marque um SIM, é fortemente sugerida a realização da avaliação clínica e médica. Contudo, qualquer pessoa pode participar de uma atividade física de esforço moderado, respeitando as restrições médicas.

O PAR-Q foi elaborado para auxiliar você a se auto-ajudar. Os exercícios praticados regularmente estão associados a muitos benefícios de saúde. Completar o PAR-Q representa o primeiro passo importante a ser tomado, principalmente se você está interessado em incluir a atividade física com maior freqüência e regularidade no seu dia a dia.

O bom senso é o seu melhor guia ao responder estas questões. Por favor, leia atentamente cada questão e marque SIM ou NÃO:

SIM NÃO

1. Alguma vez seu médico disse que você possui algum problema cardíaco e recomendou que você só praticasse atividade física sob prescrição médica?

2. Você sente dor no tórax quando pratica uma atividade física?

3. No último mês você sentiu dor torácica quando não estava praticando atividade física?

4. Você perdeu o equilíbrio em virtude de tonturas ou perdeu a consciência quando estava praticando atividade física?

5. Você tem algum problema ósseo ou articular que poderia ser agravado com a prática de atividades físicas?

6. Seu médico já recomendou o uso de medicamentos para controle da sua pressão arterial ou condição cardiovascular?

7. Você tem conhecimento de alguma outra razão física que o impeça de participar de atividades físicas?

\section{Declaração de Responsabilidade}

Assumo a veracidade das informações prestadas no questionário "PAR-Q" e afirmo estar liberado(a) pelo meu médico para participação em atividades físicas.

Nome do/a participante:

Data: / / / 2014

Assinatura: 